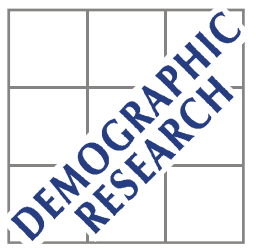

Demographic Research a free, expedited, online journal of peer-reviewed research and commentary in the population sciences published by the Max Planck Institute for Demographic Research Konrad-Zuse Str. 1, D-18057 Rostock · GERMANY www.demographic-research.org

DEMOGRAPHIC RESEARCH

VOLUME 21, ARTICLE 11, PAGES 289-340

PUBLISHED 10 SEPTEMBER 2009

http://www.demographic-research.org/Volumes/Vol21/11/

DOI: 10.4054/DemRes.2009.21.11

Research Article

Sexual behaviour patterns in South Africa and their association with the spread of HIV:

Insights from a mathematical model

Leigh F. Johnson

Rob E. Dorrington

Debbie Bradshaw

Victoria Pillay-Van Wyk

Thomas M. Rehle

(C) 2009 Leigh F. Johnson et al.

This open-access work is published under the terms of the Creative Commons Attribution NonCommercial License 2.0 Germany, which permits use, reproduction \& distribution in any medium for non-commercial purposes, provided the original author(s) and source are given credit. See http:// creativecommons.org/licenses/by-nc/2.0/de/ 


\section{Table of Contents}

1 Introduction $\quad 290$

2 Methods 291

2.1 Demographic assumptions 292

$2.2 \quad$ Sexual behaviour assumptions $\quad 292$

2.2.1 Rates of sexual debut 294

2.2.2 Rates of short-term partnership formation 294

2.2.3 Rates of marriage 296

2.2.4 Average durations of partnerships 297

$\begin{array}{lll}2.2 .5 & \text { Commercial sex } & 297\end{array}$

2.2.6 Preferences regarding partner age and risk group 298

$\begin{array}{lll}2.2 .7 & \text { Frequency of sex } & 299\end{array}$

2.2.8 Condom use 300

2.2.9 The effect of HIV symptoms and treatment on sexual behaviour $\quad 300$

$\begin{array}{lll}2.3 & \text { HIV/AIDS assumptions } & 301\end{array}$

$\begin{array}{lll}2.4 & \text { Statistical analysis } & 303\end{array}$

$\begin{array}{lll}2.5 & \text { Behaviour change scenarios } & 305\end{array}$

3 Results 306

3.1 Comparison of prior and posterior distributions 306

3.2 Comparison with HIV prevalence data and sexual behaviour data 307

3.3 The effect of AIDS morbidity and mortality on sexual behaviour 311

3.4 The profile of new HIV infections, by sexual risk behaviour 312

$\begin{array}{lll}3.5 & \text { The effect of changes in sexual behaviour } & 314\end{array}$

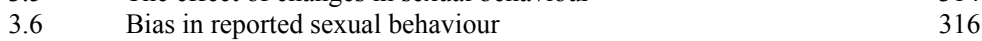

$\begin{array}{lll}4 & \text { Discussion } & 317\end{array}$

$\begin{array}{ll}\text { References } & 324\end{array}$ 


\title{
Sexual behaviour patterns in South Africa and their association with the spread of HIV: Insights from a mathematical model
}

\author{
Leigh F. Johnson ${ }^{1}$ \\ Rob E. Dorrington ${ }^{2}$ \\ Debbie Bradshaw ${ }^{3}$ \\ Victoria Pillay-Van Wyk ${ }^{4}$ \\ Thomas M. Rehle ${ }^{5}$
}

\begin{abstract}
This paper aims to quantify the effects of different types of sexual risk behaviour on the spread of HIV in South Africa. A mathematical model is developed to simulate changes in numbers of sexual partners, changes in marital status, changes in commercial sex activity, and changes in the frequency of unprotected sex over the life course. This is extended to allow for the transmission of HIV, and the model is fitted to South African HIV prevalence data and sexual behaviour data. Results suggest that concurrent partnerships and other non-spousal partnerships are major drivers of the HIV/AIDS epidemic in South Africa.
\end{abstract}

\footnotetext{
${ }^{1}$ Centre for Actuarial Research, University of Cape Town. Private Bag X3. Rondebosch 7701, South Africa. Phone: +27 21650 5761. Fax: +27 21650 5937. E-mail: Leigh.Johnson@uct.ac.za.

${ }^{2}$ Centre for Actuarial Research, University of Cape Town.

${ }^{3}$ Burden of Disease Research Unit, South African Medical Research Council.

${ }^{4}$ Social Aspects of HIV/AIDS and Health, Human Sciences Research Council.

${ }^{5}$ Social Aspects of HIV/AIDS and Health, Human Sciences Research Council.
} 


\section{Introduction}

Understanding the relationship between sexual behaviour and the risk of HIV infection is critical to the development of HIV prevention strategies. Ideally, policymakers should have detailed knowledge of the relative numbers of new HIV infections currently occurring in different sub-populations and risk groups if they are to respond effectively (Bertozzi et al. 2008; Piot et al. 2008). However, measuring numbers of new HIV infections occurring in different risk groups through surveys is challenging, and, in view of the complexities involved, simulation models that are calibrated to available epidemiological data may provide an acceptable alternative method of assessing the relative significance of different risk behaviours (Bertozzi et al. 2008). Mathematical models can also be used to assess the likely effects of different types of behavioural change (Garnett and Anderson 1995; Korenromp et al. 2000; Bracher, Santow, and Watkins 2004; Hallett et al. 2007), and can play an important role in determining whether observed changes in HIV prevalence are attributable to changes in sexual behaviour (Hallett et al. 2006).

However, there are several difficulties associated with using mathematical models to assess the contribution of different sexual behaviours to the transmission of HIV. First, there is often a lack of reliable sexual behaviour data for setting the sexual behaviour parameters in these models. In South Africa, for example, hardly any nationally representative sexual behaviour data were collected prior to 2000 (Eaton, Flisher, and Aarø 2003), and as a result, many early models of the HIV/AIDS epidemic in South Africa were forced to rely on fairly arbitrary assumptions about sexual behaviour (Doyle and Millar 1990; Schall 1990; Groeneveld and Padayachee 1992; Johnson and Dorrington 2006).

Even when sexual behaviour data are available, these are often affected by social desirability bias and recall bias. Sexual behaviour data have traditionally been captured in face-to-face interviews (FTFIs), but such interviews have been shown to elicit significantly lower reported numbers of sexual partners when compared with recently developed interview formats that are more impersonal and anonymous (Ghanem et al. 2005; Kissinger et al. 1999; Rogers et al. 2005; Mensch, Hewett, and Erulkar 2003; Gregson et al. 2004). Studies have also shown that prompting individuals with additional questions can lead to enhanced recall of past sexual relationships (Brewer et al. 2005). Although a number of mathematical models have been parameterized on the assumption that individuals report their sexual behaviour accurately in FTFIs (Dunkle et al. 2008; Merli et al. 2006; Oster 2005; Leclerc and Garenne 2007), this assumption is questionable in light of the recent evidence regarding social desirability bias. Other models that are calibrated to sexual behaviour data have allowed for bias, implicitly or 
explicitly, but have not considered the extent of the uncertainty regarding this bias (Van der Ploeg et al. 1998).

A further difficulty in using deterministic models to assess the contribution of different risk behaviours to the spread of HIV is that most deterministic models are not sufficiently detailed to provide meaningful insights into sexual behaviour. With a few exceptions (Bongaarts 1989; John 1991), most deterministic models do not represent spousal and non-spousal relationships separately. Although heterogeneity in sexual behaviour is usually allowed for by dividing the sexually active population into 'risk groups', deterministic models typically assume that individuals do not move between risk groups over time, and hence conflate inter-individual and within-individual heterogeneity in HIV risk behaviour. Deterministic models also generally do not allow for concurrent sexual partnerships explicitly, although efforts have been made to extend pair formation models to include the formation of sexual partner 'triples' (Ferguson and Garnett 2000; Bauch and Rand 2000; Eames and Keeling 2004). The implicit assumption of 'serial monogamy' is an unfortunate limitation in view of the potentially significant role of concurrent partnerships in the epidemiology of HIV in Africa (Halperin and Epstein 2004; Morris and Kretzschmar 1997).

The objective of this paper is to estimate the extent to which different types of sexual risk behaviour are promoting the spread of HIV in South Africa, using a deterministic HIV/AIDS model. This paper also aims to extend the standard deterministic model of sexual behaviour to allow for changes in numbers of sexual partners, changes in commercial sex activity, and changes in marital status over the life course. In addition, this paper proposes a method for fitting a deterministic model of sexual behaviour to sexual behaviour data, using a Bayesian approach to quantify uncertainty regarding the key sexual behaviour parameters.

\section{Method}

The sections that follow describe the demographic assumptions and assumptions about sexual behaviour and HIV transmission. For those parameters that are considered particularly difficult to estimate, prior distributions are specified to represent the ranges of uncertainty around the parameter values. These prior distributions are incorporated in a Bayesian analysis, the aim of which is to integrate the prior distributions with the HIV prevalence data and sexual behaviour data, in order to produce posterior estimates of model parameters and model outputs. A more detailed description of the model and the statistical analysis is available elsewhere (Johnson 2008). 


\subsection{Demographic assumptions}

The basis of the model is a cohort component projection model, with the South African population divided by age (in five-year age groups) and sex. The projection begins at the middle of 1985, a few years ahead of the first reported heterosexual AIDS cases in South Africa (Schoub et al. 1988). Assumptions about fertility, non-AIDS mortality, and the 1985 population profile are obtained from the 'lite' version of the ASSA2003 AIDS and Demographic Model, a model of the South African HIV/AIDS epidemic (Dorrington et al. 2006). Births and movements between age cohorts are calculated at annual intervals, while deaths and movements between sexual activity states and HIV states are calculated at monthly intervals. Further details on the demographic assumptions and the method used to determine the profile of the population at the start of the projection are contained in a supplementary data file on the journal website ('SupplementaryData.xls').

\subsection{Sexual behaviour assumptions}

Sexual behaviour is modelled by dividing the population into two sexual activity classes: individuals who have a propensity to engage in commercial sex and/or concurrent partnerships ('high risk'), and individuals who are serially monogamous and never engage in commercial sex ('low risk'). The proportion of the population in the high risk group is set at $35 \%$ in males and $25 \%$ in females, based on detailed sexual behaviour data collected in communities with high HIV prevalence (Dunkle et al. 2004; Jewkes et al. 2002). Nationally representative survey data suggest that the proportion of individuals who have multiple current partners is likely to be lower, e.g., $12 \%-18 \%$ among unmarried men and 1\%-3\% among unmarried women in the 2005 Human Sciences Research Council (HSRC) national household survey (Shisana et al. 2005). However, these are likely to be underestimates of the proportions of individuals with a propensity for concurrent partnerships, partly because of underreporting in FTFIs (i.e., social desirability bias), and partly because individuals with a propensity for concurrent partnerships do not have multiple partners all the time (Carter et al. 2007).

Within each of the two risk groups, several sexual activity states are defined, based on the nature of the relationship(s) the individual is currently in. Figure 1, for example, shows the states that are defined for women in the high risk group. Three types of sexual relationship are modelled: short-term relationships, long-term (spousal) relationships, and contacts between commercial sex workers and clients. It is assumed that all spousal relationships start off as short-term relationships, i.e., it is only possible to enter the married state from the short-term relationship state. For the sake of 
simplicity, it is assumed that individuals in the high risk group never have more than two current partners, though high risk men can continue to have contact with sex workers when they have two other partners. No allowance is made for polygyny, since it is relatively uncommon in South Africa (Budlender, Chobokoane, and Simelane 2004). The multi-state model used for men in the high risk group is identical to that shown in Figure 1, except that there is no 'sex worker' state. The model of sexual behaviour in the male and female low risk groups is the same as that shown in Figure 1, but with the states represented by the shaded cells omitted. A detailed mathematical description of the model is given in Appendix A.

\section{Figure 1: Multi-state model of sexual behaviour of 'high risk' females}

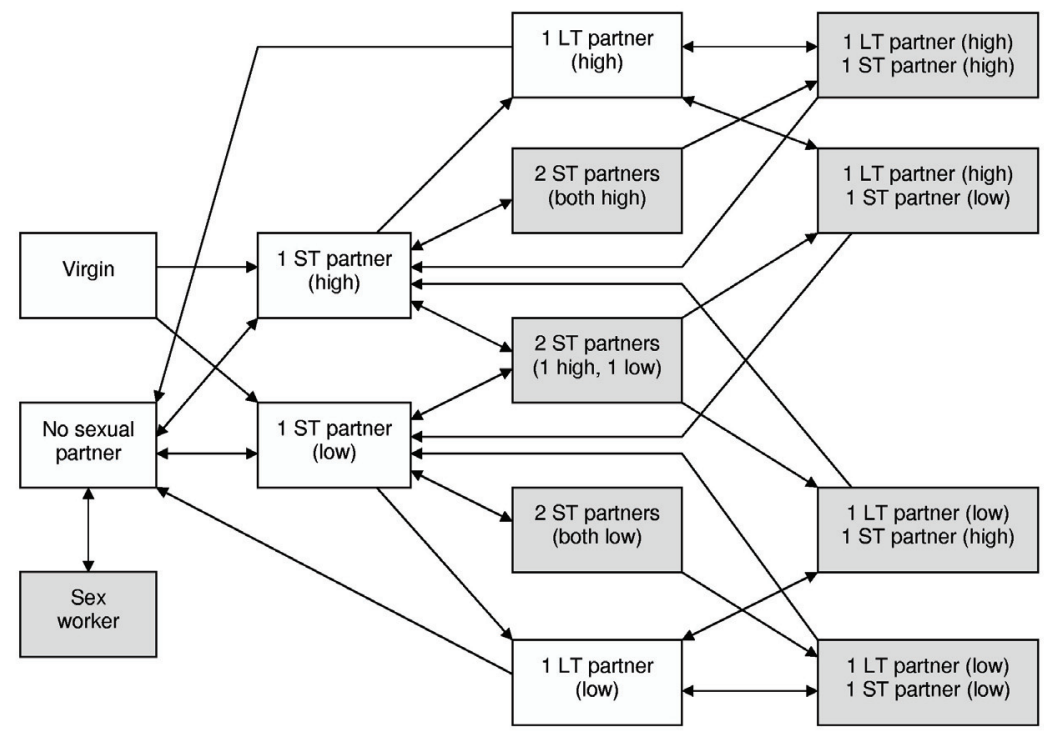

LT = long-term (spousal). ST = short-term (non-spousal). 'High' and 'low' refer to the risk group of the sexual partner. Similar states are defined for low risk females, but shaded cells are relevant only to the high risk group, i.e., movements into these states do not occur if the woman is in the low risk group. Each of the above states is divided into separate states for each five-year age group, and the state defined for each age group is further divided into six HIV states (one for HIV-negative individuals, and five for the HIV-positive states shown in Table 2). Birth, death, movements between age categories, and movements between HIV states are not shown. The same modelling approach is used in high risk males and low risk males, except that the 'sex worker' state is omitted. 


\subsubsection{Rates of sexual debut}

Assumed rates of sexual debut in the high risk group are shown in Table 1. Studies conducted in South Africa and Zimbabwe suggest that the rate at which 'low risk' individuals (however they may be defined) initiate their first sexual contact is typically between $20 \%$ and $60 \%$ of that in 'high risk' individuals (Dunkle et al. 2004; Mpofu et al. 2006; Pettifor et al. 2004b). It is therefore assumed that virgins with no propensity for multiple partnerships acquire their first sexual partner at a rate equal to half of that in virgins who subsequently enter the high risk group. The rates of sexual debut for the high risk group, shown in Table 1, have been determined in such a way that the overall levels of sexual experience for high and low risk groups combined are consistent with the reported rates of sexual experience in the 2005 HSRC household survey, based on the assumption that young women underreport sexual experience, and that young men slightly exaggerate their sexual experience (Mensch, Hewett, and Erulkar 2003; Hewett, Mensch, and Erulkar 2004; Turner et al. 1998). All individuals are assumed to be sexually experienced by age 30 .

\subsubsection{Rates of short-term partnership formation}

The parameter $c_{g, i, j, l}^{s}(x)$ is defined as the rate at which an individual of sex $g$ wishes to form new short-term partnerships if they are in risk group $i$, aged $x$, in HIV disease state $s$, and in relationship type $l$ with a partner in group $j$ (if the individual is currently single, $j=0$ and the $l$ subscript is omitted). This parameter is specified for a 'baseline' group (single HIV-negative individuals in the high risk group, who are aged 15 to 19), and a series of multiplicative adjustments are then specified to allow for the effects of age, risk group, HIV disease stage, and nature of current relationship(s). Based on data from pregnant teenagers who reported lengths of time between recent sexual partnerships (Jewkes et al. 2001), it is assumed that the rate of partner acquisition in single, sexually experienced, high risk women aged 15-19 is 14.6 per annum, which is equivalent to a mean interval between partnerships of 25 days. Since rates of secondary abstinence are typically higher in young men than in young women (Shisana et al. 2005; Reproductive Health Research Unit 2004; Human Sciences Research Council 2002), the corresponding rate for single, sexually experienced, high risk men in the 1519 age group is assumed to be half of that in women, i.e., 7.3 per annum.

To allow for the effect of age on the rate of partner acquisition, the rates of partner acquisition at different ages are assumed to be proportional to gamma densities. Initial maximum likelihood fits of the model to age-specific HIV prevalence data and sexual behaviour data produced gamma densities that were reasonably stable across a range of 
scenarios, and the parameters obtained from the average of these fits are used as the default age-specific rates of short-term partner acquisition in the model. These rates are shown in Table 1.

Table 1: $\quad$ Sexual behaviour parameters, by age and sex

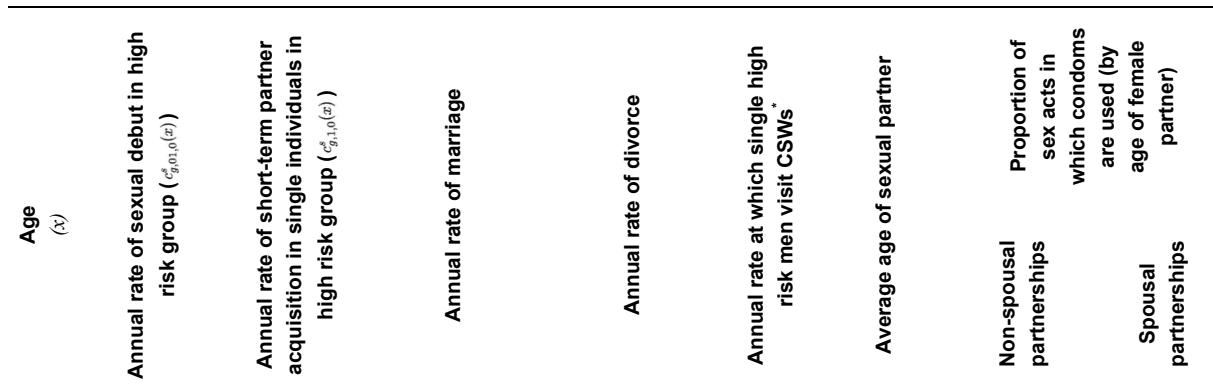

\begin{tabular}{|c|c|c|c|c|c|c|c|c|c|c|c|c|c|c|c|}
\hline & $M$ & $F$ & $\mathrm{M}$ & $\mathrm{F}$ & $M$ & $F$ & $M$ & $\mathrm{~F}$ & & $M$ & $\mathrm{~F}$ & 1985 & 2010 & 1985 & 2010 \\
\hline $10-14$ & 0.01 & 0.05 & 0.6 & 1.4 & - & - & - & - & 0.29 & 12.5 & 15.8 & 0.011 & 0.537 & - & - \\
\hline $15-19$ & 0.27 & 0.52 & 7.3 & 14.6 & 0.004 & 0.020 & 0.0003 & 0.0067 & 1.61 & 17.0 & 20.9 & 0.009 & 0.505 & 0.004 & 0.180 \\
\hline $20-24$ & 0.82 & 0.91 & 15.9 & 23.3 & 0.036 & 0.073 & 0.0163 & 0.0197 & 2.28 & 21.0 & 26.2 & 0.008 & 0.474 & 0.004 & 0.162 \\
\hline $25-29$ & 1.00 & 1.00 & 20.6 & 21.5 & 0.117 & 0.100 & 0.0252 & 0.0240 & 2.17 & 25.1 & 31.7 & 0.007 & 0.443 & 0.003 & 0.146 \\
\hline $30-34$ & - & - & 20.8 & 15.2 & 0.128 & 0.092 & 0.0250 & 0.0236 & 1.70 & 29.0 & 37.0 & 0.007 & 0.412 & 0.003 & 0.131 \\
\hline $35-39$ & - & - & 18.0 & 9.2 & 0.119 & 0.078 & 0.0218 & 0.0186 & 1.18 & 33.2 & 42.2 & 0.006 & 0.383 & 0.003 & 0.117 \\
\hline $40-44$ & - & - & 14.0 & 5.0 & 0.105 & 0.063 & 0.0182 & 0.0160 & 0.76 & 38.0 & 46.7 & 0.005 & 0.354 & 0.002 & 0.105 \\
\hline $45-49$ & - & - & 10.2 & 2.5 & 0.094 & 0.051 & 0.0145 & 0.0114 & 0.46 & 43.3 & 51.4 & 0.004 & 0.325 & 0.002 & 0.094 \\
\hline $50-54$ & - & - & 7.1 & 1.2 & 0.087 & 0.041 & 0.0109 & 0.0077 & 0.27 & 48.0 & 55.7 & 0.004 & 0.299 & 0.002 & 0.084 \\
\hline $55-59$ & - & - & 4.7 & 0.5 & 0.081 & 0.031 & 0.0071 & 0.0050 & 0.15 & 52.3 & 60.2 & 0.003 & 0.273 & 0.002 & 0.075 \\
\hline $60-64$ & - & - & 3.0 & 0.2 & 0.077 & 0.023 & 0.0045 & 0.0028 & 0.08 & 56.8 & 64.7 & 0.003 & 0.249 & 0.001 & 0.066 \\
\hline $65-69$ & - & - & 1.9 & 0.1 & 0.073 & 0.017 & 0.0036 & 0.0018 & 0.05 & 59.1 & 69.2 & 0.003 & 0.226 & 0.001 & 0.059 \\
\hline $70-74$ & - & - & 1.1 & 0.0 & 0.069 & 0.013 & 0.0020 & 0.0006 & 0.02 & 64.9 & 73.5 & 0.002 & 0.205 & 0.001 & 0.053 \\
\hline $75-79$ & - & - & 0.7 & 0.0 & 0.066 & 0.010 & 0.0015 & 0.0005 & 0.01 & 69.6 & 77.6 & 0.002 & 0.186 & 0.001 & 0.047 \\
\hline $80-84$ & - & - & 0.4 & 0.0 & 0.064 & 0.007 & 0.0015 & 0.0005 & 0.01 & 73.1 & 81.8 & 0.002 & 0.167 & 0.001 & 0.041 \\
\hline $85+$ & - & - & 0.2 & 0.0 & 0.062 & 0.005 & 0.0015 & 0.0005 & 0.00 & 74.4 & 85.6 & 0.002 & 0.151 & 0.001 & 0.037 \\
\hline
\end{tabular}

Notes: * Rates vary slightly depending on assumed ratio $c_{1,1, j, l}^{s}(x) / c_{1,1,0}^{s}(x)$, which has been set at 0.65 for $I=1$ and 0.35 for $I=2$ for the purpose of illustration. 
The rate at which low risk individuals acquire new partners is assumed to be a constant multiple of the corresponding rate at which single high risk individuals acquire new partners. This multiple, $c_{g, 2,0}^{s}(x) / c_{g, 1,0}^{s}(x)$, differs for males and females, but is assumed to be constant with respect to age and HIV disease stage. Although there are no published data indicating plausible values for this multiple, it would be expected that the multiple would be less than 1 , and a uniform $(0,1)$ prior has therefore been assigned to this parameter, for both males and females.

High risk individuals are assumed to acquire new partners at a lower rate if they already have one partner than if they are single. The multiple $c_{g, 1, j, l}^{s}(x) / c_{g, 1,0}^{s}(x)$ is specified separately for males and females in non-spousal $(l=1)$ and spousal $(l=2)$ relationships, but is assumed to be constant with respect to the individual's age, HIV disease stage, and the risk group of his or her partner. As there are no published data indicating the likely magnitudes of these parameters, uniform $(0,1)$ priors have been assigned to each of the four parameters.

Since the parameter $c_{g, j, j, l}^{s}(x)$ determines the rate at which an individual wishes to acquire new partners, it is necessary to apply a balancing factor to this rate in order to achieve consistency between the number of new partnerships formed by men in risk group $i$ with women in risk group $j$, and the number of new partnerships formed by women in risk group $j$ with men in risk group $i$. This balancing factor, defined in Appendix A, is updated on a monthly basis, as the relative numbers of males and females in different sexual behaviour states change.

\subsubsection{Rates of marriage}

Rates of marriage, by age and sex, are set in such a way that the modelled proportions of individuals who are married at each age are roughly consistent with the corresponding proportions from the 1996 Census, the 2001 Census, and the 2007 Community Survey. Following the convention in the Demographic and Health Surveys, 'marriage' refers to both formal marriages and cohabiting relationships. The resulting assumed rates of marriage at each age are shown in Table 1. Although average rates of marriage at each age are constrained to remain constant at the levels shown in Table 1, rates of marriage at a given age vary in relation to the current number of non-spousal partners and the individual's risk group. As noted previously, individuals can only enter the married state from the short-term partnership state, and thus the rate of marriage is assumed to be proportional to the number of current short-term partnerships, after controlling for age, sex, and risk group. 


\subsubsection{Average durations of partnerships}

African surveys in which respondents are asked about the durations of recent nonspousal relationships have generally suggested average durations of between three and 12 months (Nnko et al. 2004; Ferry et al. 2001; Jewkes et al. 2001). On the basis of these studies, it is assumed that the average duration of non-spousal relationships is six months, and that the rate of relationship termination is constant with respect to the relationship duration.

Registered divorce statistics are used to approximate rates of divorce in South Africa, although these are likely to understate the true rate at which spousal relationships are terminated. This is partly because reporting of divorces is incomplete (Bah 1999), but largely because our definition of spousal relationships includes unmarried cohabiting partners, who might be expected to have a higher rate of separation than couples in formal marriages (Porter et al. 2004). In addition, many formal marriages end in separation, which may precede divorce by several years (van Tonder 1985), and union dissolution is therefore often not reflected in published divorce statistics. To allow for this understatement, it is assumed that rates of spousal union dissolution are two times the age-specific rates of divorce estimated from published divorce statistics in 2004 (Statistics South Africa 2006). The resulting rates of spousal union dissolution are shown in Table 1. Allowance is also made for dissolution of partnerships due to the death of either partner.

\subsubsection{Commercial sex}

No national South African survey has measured the proportion of the male population engaging in commercial sex, but the average proportion of men reporting sex with sex workers in the last 12 months has been estimated at 6.3\% in other Southern African countries (Caraël et al. 2006). This is probably an underestimate of the true proportion of men having sex with sex workers, as men appear to underreport such sexual contacts in FTFIs (Des Jarlais et al. 1999; Lau, Tsui, and Wang 2003; Morison et al. 2001). Taking into account the likely underreporting, assumptions about the rates at which men visit sex workers have been set in such a way that the average annual number of sex worker contacts for men in the 15-49 age group is roughly double the average frequency of sex worker contacts estimated by Caraël et al. for Southern Africa. Caraël et al. also estimate that the frequency of sex worker contact among males aged 15-24 is on average about 1.3 times that of males aged 25-49 in Southern Africa. This information is used to determine gamma density scaling factors, which are in turn used to calculate the relative frequencies of sex worker contact at different ages. Table 1 
shows the assumed annual frequencies of sex worker contact, by age, for men in the high risk group who are single. Relative to men who currently have no sexual partner, the frequency of sex worker contact is assumed to be reduced by $50 \%$ in men who have one non-spousal partner, by $70 \%$ in men who have one spousal partner, by $80 \%$ in men who have two non-spousal partners, and by $90 \%$ in men who have a spousal partner as well as a non-spousal partner.

Women tend to engage in commercial sex work for short periods, mainly out of economic necessity, and the average duration of sex work in African countries is typically estimated to be between one and four years (Rees et al. 2000; Morison et al. 2001; Abdool Karim et al. 1995). It is therefore assumed that sex workers discontinue sex work at a constant rate of 0.5 per annum. Women are assumed to become sex workers at a rate sufficient to meet the male demand for commercial sex, with the relative rates of entry into sex work at different ages being determined in such a way that the age distribution of sex workers is consistent with that observed in a study of sex workers in Johannesburg (Rees et al. 2000). Studies suggest that South African sex workers usually have between 20 and 25 sex acts with clients per week (Ramjee, Weber, and Morar 1999; Abdool Karim et al. 1995; Rees et al. 2000; Varga 1997a), and on the basis of this evidence, it is assumed that sex workers have an average of 1,000 sex acts with clients per annum.

\subsubsection{Preferences regarding partner age and risk group}

Mathematical models of sexually transmitted infections traditionally define patterns of mixing between risk groups in terms of a 'degree of assortative mixing' parameter, $\varepsilon$, which can take on any value between 0 and 1 (Garnett and Anderson 1996). When $\varepsilon$ is 0 , sexual mixing is said to be perfectly assortative, i.e., individuals only form relationships with partners in the same group. When $\varepsilon$ is 1 , sexual mixing is random, and individuals have no preferences regarding the sex activity class of their partner. Data from industrialized nations suggest $\varepsilon$ values of between 0.65 and 0.92 (Laumann et al. 1994; Manhart et al. 2002; Garnett et al. 1996; Granath et al. 1991), and data from Botswana suggest a value of 0.53 (Carter et al. 2007). However, it is difficult to estimate $\varepsilon$ reliably from empirical data, and Ghani et al. (1998) demonstrate that sampling bias is likely to lead to significant overestimation of $\varepsilon$. There is thus substantial uncertainty regarding the true value of $\varepsilon$, and this parameter has therefore been assigned a beta prior with a mean of 0.6 and a standard deviation of 0.15 .

Proportions of partners in each five-year age band are specified separately for males and females, and for each five-year age band. For women, these proportions are weighted averages of the proportions of spousal partners in each age group, as 
estimated from the 1998 DHS (Department of Health 1999), and the proportions of non-spousal partners in each age group, as estimated from non-spousal partner age differences in South African studies (Williams et al. 2000; Hallman 2004; Kelly 2000; Shisana et al. 2005). The total numbers of partnerships between women of age $x$ and men of age $y$ are tabulated, and this is used to determine the proportion of female partners in each age group, for men of age $y$. The resulting estimates of the mean partner age, for men and women separately, are shown in Table 1, and the detailed partner age distributions are shown in the supplementary data file.

\subsubsection{Frequency of sex}

The method most commonly used to determine coital frequency in sexual behaviour surveys is to ask individuals about the number of times they have had sex in the last four weeks. Estimates of the daily probability of sex in married women obtained using this method typically lie between 0.098 and 0.240 in Southern and Eastern Africa (Brown 2000; Blanc and Rutenberg 1991). However, these reported frequencies are likely to overestimate the true coital frequency among married individuals, as several studies have found that when coital frequency is recorded over shorter time intervals, over which there is likely to be less recall bias, reported coital frequency is lower (Hornsby and Wilcox 1989; Lagarde, Enel, and Pison 1995; Høgsborg and Aaby 1992). It has also been found that coital frequencies among married women reduce significantly as they age (Brewis and Meyer 2005). On the basis of these studies, it is assumed that the average marital coital frequency among married women aged 20 to 24 is five times per month, and that this frequency reduces exponentially with respect to age, halving with every 20 -year increase in age. Coital frequencies in married men are calculated to be consistent with these assumptions.

In contrast to married individuals, unmarried individuals and individuals with high rates of partner change tend to report numbers of sex acts in the last four weeks close to or less than those estimated over shorter time intervals (Leigh, Gillmore, and Morrison 1998; Allen et al. 2007; McAuliffe, DiFranceisco, and Reed 2007). In a survey of South African youth, Kelly (2000) found that youth who were sexually active and in noncohabiting relationships reported an average of three sex acts per four-week period, and this estimate of three sex acts per month is used in the model for all non-spousal partnerships. The assumed frequencies of sex in spousal and non-spousal partnerships result in numbers of sex acts that are roughly consistent with the aggregate reported coital frequencies in the 15-24 and 25-49 age bands in the 2005 HSRC household survey (Shisana et al. 2005), after allowing for recall bias in spousal relationships. 


\subsubsection{Condom use}

Levels of condom use are assumed to depend on the individual's age and sex and the nature of the relationship they are currently in. Levels of condom use are also assumed to increase over time, as there is strong evidence of trends towards greater condom use in South Africa (Katz and Low-Beer 2008), coinciding with increasing levels of condom distribution (Myer 2005). Table 1 shows the assumed proportions of sex acts in which condoms are used, by the age of the female partner and the relationship type, for two years: 1985 and 2010. The increase in condom use is phased in between these two dates using cumulative Weibull distributions with medians around 1997. The resulting levels of condom use, by age, year, and relationship type, are $40 \%$ lower than nationally representative survey estimates of the proportion of individuals using a condom at last sex (Shisana et al. 2005; Department of Health 2004; Department of Health 1999). This is because survey estimates of the proportion of individuals using a condom at last sex are likely to overestimate the true proportion of recent sex acts that are protected, since individuals who have sex infrequently are more likely to use condoms than those who have sex frequently (Pettifor et al. 2004a; Hargreaves et al. 2007). The difference of $40 \%$ is consistent with the finding of Meekers and Van Rossem (2005) that the proportion of sex acts in the last day that were protected is typically around $40 \%$ lower than the proportion of individuals reporting use of a condom at last sex.

Separate assumptions are made about the frequency of condom use in contacts between commercial sex workers and their clients. The probability of condom use is assumed to increase from 0.2 in 1985 (Jochelson, Mothibeli, and Leger 1991), to 0.9 ultimately (Peltzer, Seoka, and Raphala 2004). As before, a cumulative Weibull distribution is used to phase in the increase in condom use, and this produces estimates of condom usage in the late 1990s consistent with the rates of around $60 \%$ observed at the time (Rees et al. 2000; Williams et al. 2000).

\subsubsection{The effect of HIV symptoms and treatment on sexual behaviour}

Several studies have shown that women generally have fewer sexual partners as they enter the later stages of HIV disease (Ross et al. 2004; Terceira et al. 2003; Hankins, Tran, and Lapointe 1998; Greenblatt et al. 1999), but the initiation of highly active antiretroviral treatment (HAART) is associated with a restoration of health and a resumption of sexual activity (Bunnell et al. 2006; Moatti et al. 2003). It is therefore assumed that the rates of partner acquisition stated previously are reduced by specified multiples (shown in Table 2) after individuals develop HIV-related symptoms. The same multiples are used to adjust the rates at which HIV-infected women initiate sex 
work. Evidence also suggests that sex workers are more likely to discontinue sex work in the later stages of HIV disease (McClelland et al. 2006), and the previously stated rates at which women are assumed to discontinue sex work are therefore increased by multiples shown in Table 2 if women are in more advanced stages of disease. Associated with the reductions in the rate of partner acquisition in the later stages of HIV disease are reductions in fertility. The assumed relative levels of fertility in the different HIV states (shown in Table 2) are based on estimates of the annual reduction in the rate of fertility per year of HIV infection (Johnson, Dorrington, and Matthews 2007) and the observed effects of antiretroviral treatment on fertility (Blair et al. 2004).

Table 2: HIV/AIDS assumptions

\begin{tabular}{|c|c|c|c|c|c|}
\hline Parameter & Primary HIV & Asymptomatic HIV & Pre-AIDS symptoms & Untreated AIDS & HAART \\
\hline $\begin{array}{l}\text { Average time spent } \\
\text { in stage (in years) }\end{array}$ & 0.25 & 5.16 & 4.14 & 1.96 & 13.0 \\
\hline $\begin{array}{l}\text { Infectiousness per sex act } \\
\text { (relative to stage 2) }\end{array}$ & 10 & 1 & 2.5 & 5 & 0.5 \\
\hline $\begin{array}{l}\text { Partner acquisition rate } \\
\text { (relative to uninfected) }\end{array}$ & 1 & 1 & 0.65 & 0.25 & 0.8 \\
\hline $\begin{array}{l}\text { Rate of entry into sex work } \\
\text { (relative to uninfected) }\end{array}$ & 1 & 1 & 0.65 & 0.25 & 0.8 \\
\hline $\begin{array}{l}\text { Rate of exit from sex work } \\
\text { (relative to uninfected) }\end{array}$ & 1 & 1 & 1.5 & 3 & 2 \\
\hline $\begin{array}{l}\text { Fertility rate } \\
\text { (relative to uninfected) }\end{array}$ & 1 & 0.92 & 0.80 & 0.73 & 0.94 \\
\hline
\end{tabular}

\subsection{HIV/AIDS assumptions}

To allow for changes in levels of HIV infectiousness and changes in sexual behaviour over the course of HIV infection, the model divides HIV-infected adults into five different HIV states: primary HIV infection, asymptomatic infection, pre-AIDS symptomatic infection (equivalent to WHO clinical stage 3), untreated AIDS and treated HIV (receiving HAART). It is assumed that after progressing to AIDS, a proportion of individuals start HAART immediately and the balance remain in the untreated AIDS state. The proportion of individuals who start HAART changes over time, and has been set at the same levels as estimated in the ASSA2003 AIDS and Demographic model, based on reported numbers of patients on HAART in the South African private and public health sectors (Dorrington et al. 2006). The average length of time spent in each stage is calculated by assuming an average total survival time of 11.5 years, in the absence of antiretroviral treatment, and multiplying this by estimated proportions of untreated HIV survival time spent in different WHO clinical stages 
(Johnson, Dorrington, and Matthews 2007; Johnson and Dorrington 2006). These are shown in Table 2.

There is substantial evidence to suggest that the probability of HIV transmission per act of sex reduces as the cumulative number of sex acts with the infected partner increases (Downs and De Vincenzi 1996; Padian, Shiboski, and Jewell 1990; Kaplan 1990). It is therefore assumed that HIV transmission probabilities per act of sex vary in relation to the partnership type, with HIV transmission probabilities being higher in short-term relationships. As there is much uncertainty regarding these transmission probabilities, beta prior distributions have been specified to represent the extent of the uncertainty around these parameters, and these prior distributions are shown in Table 3, together with the prior distributions for the sexual behaviour parameters. Due to the lack of HIV transmission probability estimates in Africa, high standard deviations are specified, and the prior distributions can therefore be expected to have relatively little effect on the fitting of the model. Condoms are assumed to reduce the HIV transmission probability per sex act by a factor of 0.9 (Weller and Davis 2004). The transmission probabilities are also adjusted to reflect the HIV stage of the infected partner, and Table 2 shows the relative levels of HIV infectiousness assumed for the different HIV stages. The epidemic is started in 1985 with an assumed initial HIV prevalence in the high risk group that is consistent with early antenatal survey results (Küstner, Swanevelder, and van Middelkoop 1994). 
Table 3: Comparison of prior and posterior distributions

\begin{tabular}{|c|c|c|}
\hline Parameter & $\begin{array}{l}\text { Prior distribution } \\
\text { (mean, } 95 \% \mathrm{Cl} \text { ) }\end{array}$ & $\begin{array}{l}\text { Posterior distribution } \\
\text { (mean, } 95 \% \mathrm{Cl})\end{array}$ \\
\hline $\begin{array}{l}\text { Male-to-female transmission probability in } \\
\text { non-spousal relationships }\end{array}$ & $0.012(0.004-0.024)^{2}$ & $0.0065(0.0044-0.0092)$ \\
\hline $\begin{array}{l}\text { Male-to-female transmission probability in } \\
\text { spousal relationships }\end{array}$ & $0.002(0.0005-0.0044)^{3}$ & $0.0024(0.0010-0.0044)$ \\
\hline $\begin{array}{l}\text { Female-to-male transmission probability in } \\
\text { non-spousal relationships }\end{array}$ & $0.010(0.0050-0.0167)^{4}$ & $0.0036(0.0024-0.0052)$ \\
\hline $\begin{array}{l}\text { Female-to-male transmission probability in } \\
\text { spousal relationships }\end{array}$ & $0.002(0.0005-0.0044)^{3}$ & $0.0017(0.0005-0.0035)$ \\
\hline Initial HIV prevalence in high risk group & $0.1 \%(0.005-0.195 \%)^{5}$ & $0.183 \%(0.141-0.199 \%)$ \\
\hline Degree of sexual mixing & $0.60(0.29-0.87)^{6}$ & $0.56(0.40-0.75)$ \\
\hline $\begin{array}{l}\text { Relative rate of partner acquisition in high risk } \\
\text { men with one non-spousal partner }{ }^{1}\end{array}$ & $0.50(0.025-0.975)^{7}$ & $0.64(0.29-0.98)$ \\
\hline $\begin{array}{l}\text { Relative rate of partner acquisition in high risk } \\
\text { women with one non-spousal partner }{ }^{1}\end{array}$ & $0.50(0.025-0.975)^{7}$ & $0.54(0.19-0.95)$ \\
\hline $\begin{array}{l}\text { Relative rate of partner acquisition in high risk } \\
\text { men with one spousal partner }{ }^{1}\end{array}$ & $0.50(0.025-0.975)^{7}$ & $0.41(0.15-0.81)$ \\
\hline $\begin{array}{l}\text { Relative rate of partner acquisition in high risk } \\
\text { women with one spousal partner }\end{array}$ & $0.50(0.025-0.975)^{7}$ & $0.17(0.04-0.37)$ \\
\hline $\begin{array}{l}\text { Relative rate of partner acquisition in low risk } \\
\text { men }^{1}\end{array}$ & $0.50(0.025-0.975)^{7}$ & $0.19(0.01-0.76)$ \\
\hline $\begin{array}{l}\text { Relative rate of partner acquisition in low risk } \\
\text { women }{ }^{1}\end{array}$ & $0.50(0.025-0.975)^{7}$ & $0.60(0.21-0.97)$ \\
\hline
\end{tabular}

Notes: ${ }^{1}$ The rate of partner acquisition is expressed as a multiple of that in high risk individuals of the same age and sex who are currently single.

${ }^{2}$ The prior distribution is beta $(5.679,467.56)$, based on two South African studies of HIV transmission probabilities in young women (Pettifor et al. 2007; Auvert et al. 2001a). In sex workers, the probability of transmission per act of sex with an infected client is assumed to be lower (0.003), based on studies of HIV incidence in sex workers (Ramjee et al. 2005; Hayes, Schulz and Plummer 1995).

${ }^{3}$ The prior distribution is beta $(3.99,1991.01)$, based on estimates of HIV transmission probabilities in cohabiting couples in East Africa (Allen et al. 1992; Gray et al. 2001).

${ }^{4}$ The prior distribution is beta $(10.99,1088.01)$, based on estimates of HIV transmission probabilities in unmarried men (Mahiane et al. 2008; Baeten et al. 2005). The probability of HIV transmission per act of sex with an infected sex worker is assumed to be higher (0.03), based on evidence from Thailand (Mastro et al. 1994).

${ }^{5}$ The prior distribution is uniform $(0,0.2 \%)$.

${ }^{6} \mathrm{~A}$ beta prior is assumed, with parameters 5.80 and 3.867 .

${ }^{7}$ The prior distribution is uniform $(0,1)$.

\subsection{Statistical analysis}

The model is fitted to data from three sources: (1) antenatal clinic HIV prevalence data from the 1997-2005 period ${ }^{6}$ for each of five age groups, (2) HIV prevalence data from a national household survey in 2005 by five-year age group and sex, and (3) data on

${ }^{6}$ Although there appears to have been an inconsistency in the weighting factors used in the 1998 survey, the published 1998 prevalence levels have been used in the statistical analysis. 
numbers of current sexual partners from the same 2005 household survey. The HIV prevalence data have been presented previously (Department of Health 2006; Shisana et al. 2005), and the method used to define the likelihood function in respect of these HIV prevalence data is described in Appendix B. The sexual behaviour data were collected in FTFIs, as part of the 2005 HSRC Household Survey, and are summarized in Table 4. The data relate to the reported numbers of sexual partners at the time of the interview, and are therefore cross-sectional rather than longitudinal or retrospective. Supposing that for a set of model parameters $\boldsymbol{\varphi}$, the predicted proportion of individuals who have $n$ partners is $P_{g, x, l}(n \mid \varphi)$ among individuals of sex $g$, aged $x$ and of marital status $l$, the statistical model for the corresponding reported proportion $\left(\psi_{g, x, l}(n)\right)$ is

$$
\ln \left(\frac{\psi_{g, x, l}(n)}{1-\psi_{g, x, l}(n)}\right)=\ln \left(\frac{P_{g, x, l}(n \mid \varphi)}{1-P_{g, x, l}(n \mid \varphi)}\right)+b_{g, l, n}+\xi_{g, x, l, n},
$$

where $b_{g, l, n}$ is a bias term, representing the extent of misreporting in FTFIs, and $\xi_{g, x, l, n} \sim$ $\mathrm{N}\left(0, \sigma_{g, x, l, n}^{2}\right)$. The $\sigma_{g, x, l, n}$ terms are the standard errors shown in Table 4. The $b_{g, l, n}$ terms are assumed to be unknown a priori and are therefore estimated directly from the data using the formula:

$$
\hat{b}_{g, l, n}=\frac{1}{5} \sum_{x}\left(\ln \left(\frac{\psi_{g, x, l}(n)}{1-\psi_{g, x, l}(n)}\right)-\ln \left(\frac{P_{g, x, l}(n \mid \varphi)}{1-P_{g, x, l}(n \mid \varphi)}\right)\right) .
$$

Due to the small numbers of individuals reporting multiple partners, the likelihood is calculated only for five age groups, and all individuals reporting multiple partners ( $n$ $>1)$ are grouped together. The likelihood function for a single observation, $\psi_{g, x, l}(n)$, is calculated as

$$
\frac{1}{\sqrt{2 \pi} \sigma_{g, x, l, n}} \exp \left(-\frac{\left(\operatorname{logit}\left(\psi_{g, x, l}(n)\right)-\operatorname{logit}\left(P_{g, x, l}(n \mid \varphi)\right)-\hat{b}_{g, l, n}\right)^{2}}{2 \sigma_{g, x, l, n}^{2}}\right) .
$$

The model is fitted to the HIV prevalence data and sexual behaviour data using a Bayesian approach. Prior distributions have been specified for those sexual behaviour and HIV transmission parameters that are considered to be particularly uncertain, as described in Sections 2.2 and 2.3. The posterior density for a particular parameter combination $\varphi$ is calculated as the product of the prior distribution for that parameter 
combination, the likelihood of $\boldsymbol{\varphi}$ in respect to the sexual behaviour data, and the likelihood of $\boldsymbol{\varphi}$ in respect to the HIV prevalence data. The posterior distribution of model predictions was simulated numerically using the Metropolis algorithm (Gelman et al. 2004), with convergence being achieved after a total run length of 100,000 simulations. All programming was done in $\mathrm{C}++$.

\section{Table 4: Percentage of individuals reporting different numbers of current} sexual partners

\begin{tabular}{|c|c|c|c|c|c|}
\hline & $15-24$ & $25-34$ & $35-44$ & $45-59$ & $60+$ \\
\hline \multicolumn{6}{|c|}{ Sexually experienced unmarried males } \\
\hline $\mathrm{N}$ & 1210 & 515 & 256 & 198 & 149 \\
\hline$\%$ reporting 0 current partners & $27.3(1.8)$ & $18.6(2.6)$ & $23.0(3.6)$ & $39.2(4.6)$ & $76.1(5.5)$ \\
\hline$\%$ reporting 1 current partner & $57.2(2.0)$ & $63.8(3.3)$ & $65.1(4.0)$ & $42.6(5.2)$ & $20.4(5.2)$ \\
\hline$\%$ reporting $>1$ current partner & $15.5(1.5)$ & $17.7(2.8)$ & $12.0(2.7)$ & $18.2(4.4)$ & $3.5(2.2)$ \\
\hline \multicolumn{6}{|c|}{ Sexually experienced unmarried females } \\
\hline $\mathrm{N}$ & 1469 & 771 & 630 & 771 & 696 \\
\hline$\%$ reporting 0 current partners & $25.1(1.8)$ & $27.4(2.3)$ & $46.0(2.8)$ & $72.4(2.4)$ & $98.7(0.5)$ \\
\hline$\%$ reporting 1 current partner & $71.9(1.8)$ & $70.8(2.3)$ & $53.1(2.8)$ & $26.8(2.4)$ & $1.3(0.5)$ \\
\hline$\%$ reporting $>1$ current partner & $3.0(0.6)$ & $1.9(0.6)$ & $0.8(0.4)$ & $0.9(0.4)$ & $0.0(-)$ \\
\hline \multicolumn{6}{|l|}{ Married males } \\
\hline $\mathrm{N}$ & 52 & 412 & 739 & 828 & 437 \\
\hline$\%$ reporting 1 current partner & $91.6(5.9)$ & $92.7(2.0)$ & $95.3(1.3)$ & $94.2(1.3)$ & $96.4(1.5)$ \\
\hline$\%$ reporting $>1$ current partner & $8.4(5.9)$ & $7.3(2.0)$ & $4.7(1.3)$ & $5.8(1.3)$ & $3.6(1.5)$ \\
\hline \multicolumn{6}{|l|}{ Married females } \\
\hline $\mathrm{N}$ & 321 & 800 & 1154 & 1160 & 461 \\
\hline$\%$ reporting 1 current partner & $98.8(0.8)$ & $99.4(0.3)$ & $99.7(0.2)$ & $99.9(0.1)$ & $100.0(-)$ \\
\hline$\%$ reporting $>1$ current partner & $1.2(0.8)$ & $0.6(0.3)$ & $0.3(0.2)$ & $0.1(0.1)$ & $0.0(-)$ \\
\hline
\end{tabular}

Individuals were asked to report the number of sexual partners they currently had at the time of the interview. Standard errors are reported in brackets.

\subsection{Behaviour change scenarios}

Although the baseline scenario allows for the effect of increases in condom usage that have already occurred in South Africa, the following scenarios are also considered for 
the purpose of assessing the likely impact of potential future changes in sexual behaviour:

- 'Halve concurrence': It is assumed that the rate at which new partners are acquired is halved among those individuals who are already in partnerships.

- 'Halve partner acquisition': The rate at which new non-spousal partners are acquired is halved, but the rate at which marriage occurs is unchanged.

- 'Halve rate of sexual debut': The rate at which virgins enter their first sexual relationship is halved (this is equivalent to a roughly two-year increase in the median age at first sex).

- 'Halve sex worker contacts': The rate at which men visit commercial sex workers is assumed to be halved.

- 'Double incidence of marriage': The age-specific rates of marriage are doubled (this is equivalent to a roughly three-year decrease in the median age at first marriage).

- 'Halve unprotected non-spousal sex': The proportion of sex acts in non-spousal relationships that are unprotected is assumed to be halved.

- 'Halve unprotected spousal sex': The proportion of sex acts in spousal relationships that are unprotected is assumed to be halved.

\section{Results}

\subsection{Comparison of prior and posterior distributions}

The prior distributions specified previously are compared with the posterior estimates of the model parameters in Table 3 in order to determine the extent to which the parameter estimates change after taking into account the HIV prevalence data and sexual behaviour data described in Section 2.4. Posterior estimates of HIV transmission probabilities in non-spousal relationships are substantially lower than the prior means, and the posterior estimates of HIV transmission probabilities suggest a significant difference between the probabilities of male-to-female and female-to-male transmission, particularly in non-spousal relationships. The posterior estimate of the degree of assortative mixing is consistent with prior beliefs (mean $0.56,95 \%$ CI: 0.40 0.75 ), but posterior estimates of other sexual behaviour parameters differ markedly from the uniform priors that have been assigned. The posterior distributions suggest that, among high risk women, the rate of partner acquisition is roughly halved if the woman is already in a non-spousal relationship, but there is a much greater reduction in the rate of partner acquisition if the woman is in a spousal relationship. Women in the 
low risk group have a rate of partner acquisition approximately $40 \%$ lower than that of their counterparts in the high risk group. Men in the low risk group, on the other hand, have a rate of partner acquisition roughly $80 \%$ lower than that of men in the high risk group.

\subsection{Comparison with HIV prevalence data and sexual behaviour data}

The model fits well to both the HIV prevalence data and the sexual behaviour data. Figure 2 shows that the posterior mean HIV prevalence levels predicted for pregnant women in each five-year age band are reasonably consistent with the results from the national antenatal clinic surveys over the 1997-2005 period, although the irregular trend in HIV prevalence observed in the 15-19 age group (particularly in 1998) is difficult to replicate. In addition, the posterior mean HIV prevalence levels for all pregnant women are consistent with data collected prior to 1997 and after 2005 (Figure 2a), although these data were not included in the likelihood definition due to differences in survey protocols prior to 1997 and after 2005. Model predictions of HIV prevalence in the general population are also consistent with levels of HIV prevalence measured in the 2005 HSRC household survey, as shown in Figures 3a and 3b. The model predictions are further validated by HIV prevalence data collected in a similar household prevalence survey conducted in 2002 (Connolly et al. 2004), although the 2002 data were not used in defining the likelihood function (Figures $3 \mathrm{c}$ and $3 \mathrm{~d}$ ).

Model predictions of proportions of individuals with more than one current partner or no current partner are compared with corresponding results from the 2005 HSRC household survey in Figure 4, after adjusting the former for the levels of reporting bias estimated using equation (2). The average posterior model estimates of proportions of individuals with different numbers of partners are, after adjusting for bias, reasonably consistent with the survey results. The model estimates of the proportions of the population who are married or in cohabiting relationships are compared with the results of the 1996 Census, the 2001 Census, and the 2007 Community Survey in Figure 5. The posterior model estimates are generally consistent with the proportions reported in the three surveys, although in the 1996 Census the proportions of older women who reported being in spousal relationships were higher than predicted by the model. In addition, the proportions of individuals in spousal relationships in the 2007 Community Survey are lower than those predicted by the model. 


\section{Figure 2: HIV prevalence in pregnant women attending public antenatal clinics}

(a) $15-49$

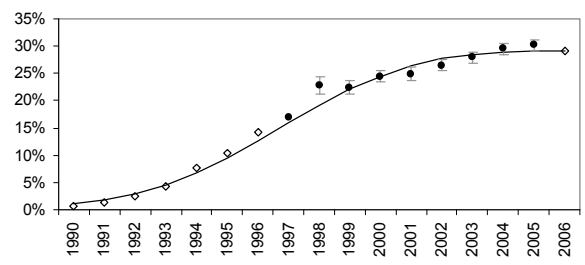

(c) 20-24

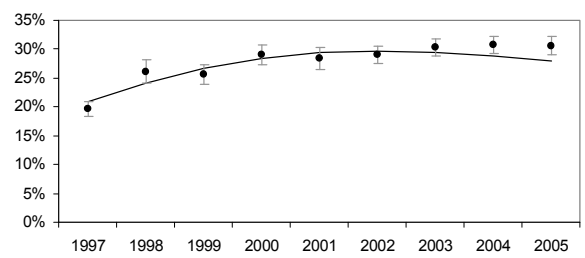

(e) $30-34$

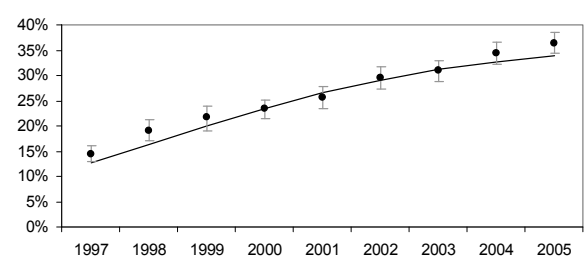

(b) $15-19$

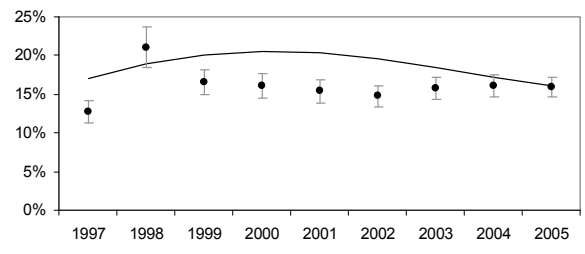

(d) $25-29$

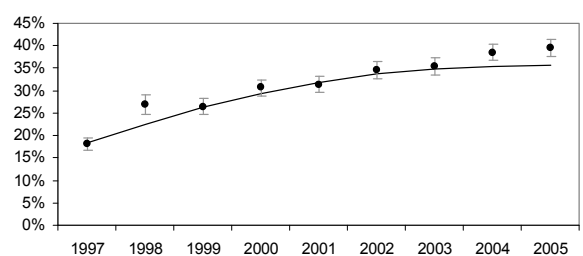

(f) $35-39$

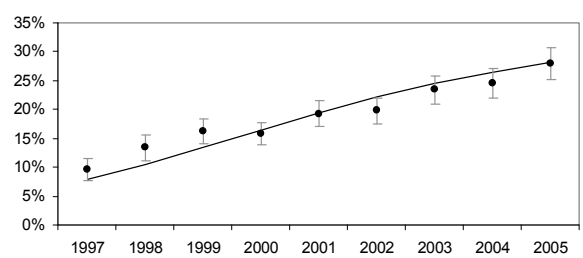

Reported prevalence levels are represented by closed circles (with 95\% confidence intervals) if used to define the likelihood function, or by open diamonds if not used in the likelihood definition. The mean of the posterior model predictions is represented by the solid black line. 


\section{Figure 3: HIV prevalence in the general population}

(a) Females, 2005

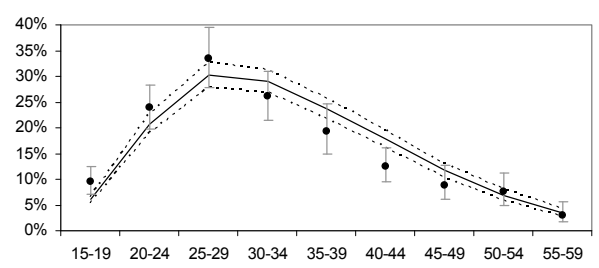

(c) Females, 2002

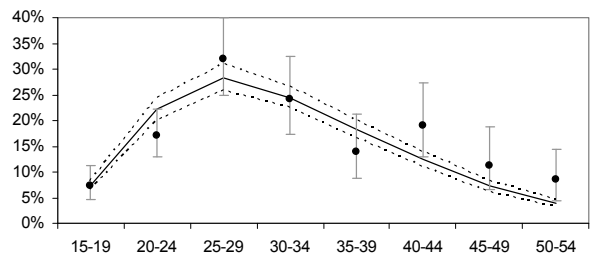

(b) Males, 2005

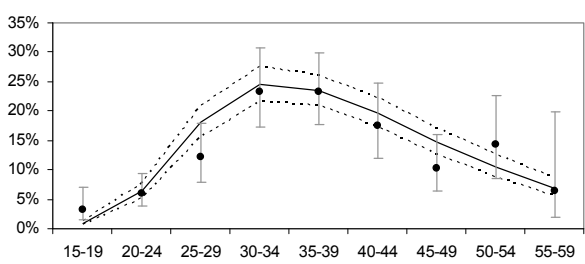

(d) Males, 2002

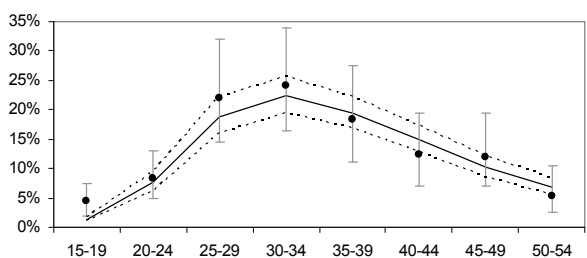

HIV prevalence levels measured in household surveys are represented by closed circles (with $95 \%$ confidence intervals). The mean of the posterior model predictions is represented by the solid black line. 2.5 and 97.5 percentiles of posterior model predictions ( $95 \%$ confidence intervals) are represented by dashed lines. 


\section{Figure 4: Sexual behaviour of sexually experienced individuals}

(a) $\%$ of unmarried males reporting $>1$ partner

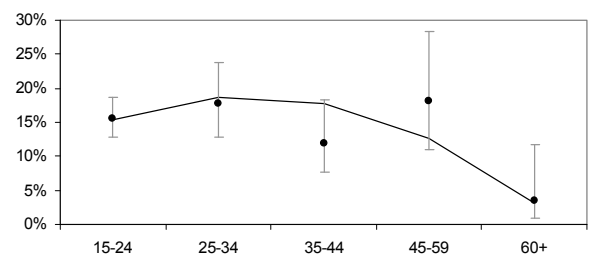

(c) $\%$ of married males reporting $>1$ partner

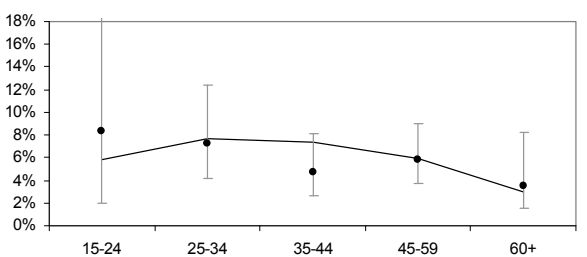

(e) \% of unmarried males reporting no partner

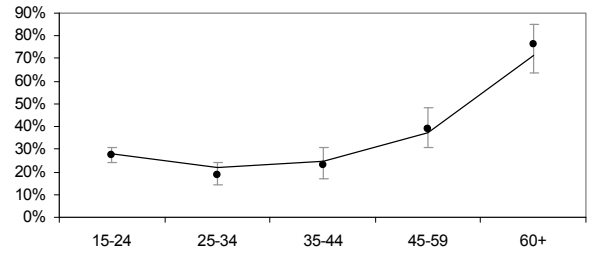

(b) $\%$ of unmarried females reporting $>1$ partner

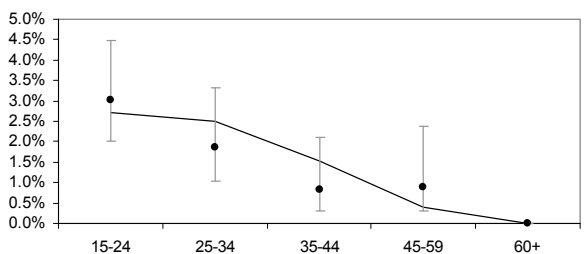

(d) \% of married females reporting $>1$ partner

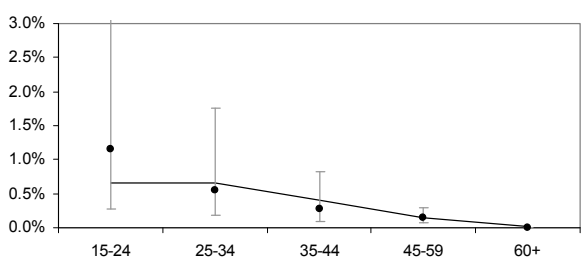

(f) \% of unmarried females reporting no current partner

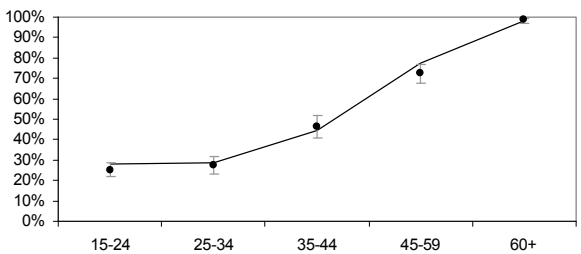

Proportions of individuals reporting different numbers of current partners are represented by closed circles (with $95 \%$ confidence intervals). The mean of the posterior model predictions, after adjustment for estimated reporting bias, is represented by the solid black line. 
Figure 5: Proportions of individuals who are married or in cohabiting relationships

(a) Males, 1996

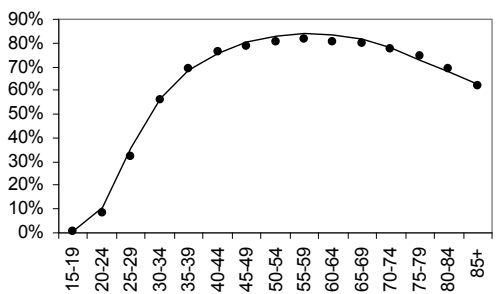

(c) Males, 2001

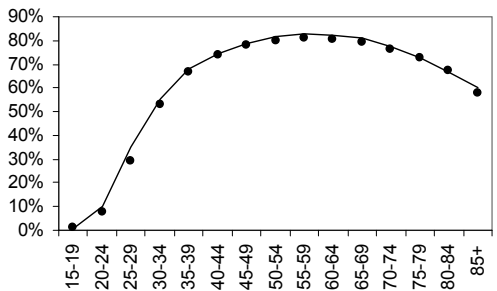

(e) Males, 2007

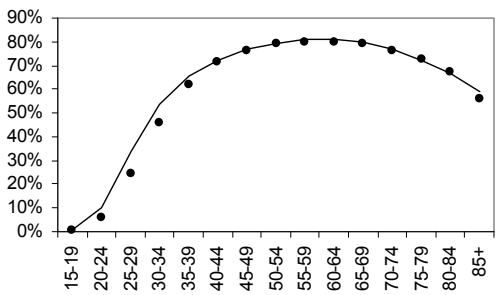

(b) Females, 1996

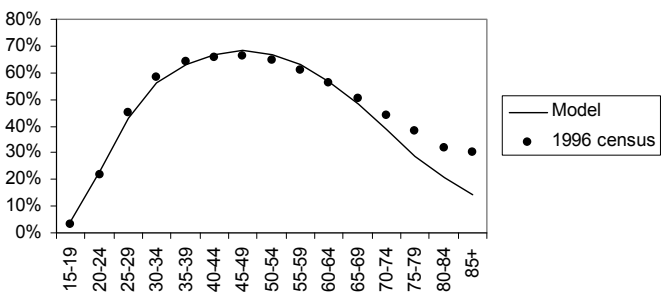

(d) Females, 2001

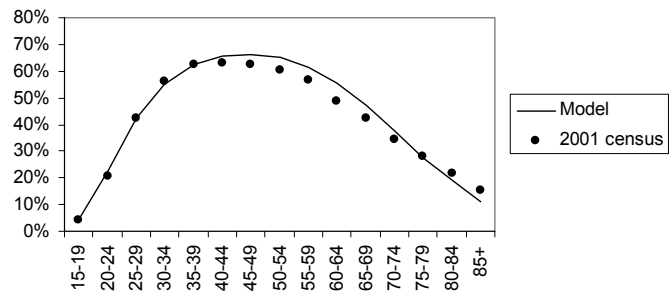

(f) Females, 2007

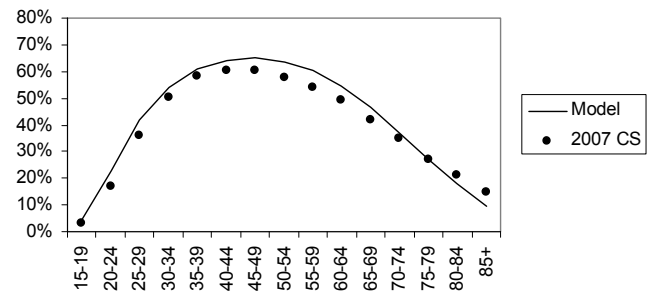

The mean of the posterior model predictions is represented by the solid black line. Reported proportions married or in cohabiting relationships are represented by closed circles.

\subsection{The effect of AIDS morbidity and mortality on sexual behaviour}

Figure 6 compares the levels of sexual risk behaviour in 1995, before significant AIDS mortality and morbidity occurred, and in 2005 , after significant increases in morbidity and mortality. The model does not allow for any deliberate behaviour change up to the current time (other than increased condom usage), and hence all of the estimated 
behaviour changes are attributable to the effects of AIDS mortality and morbidity. Figure 6 shows that AIDS has reduced significantly the proportion of men and women with multiple partners, with the reduction among men being greatest between the ages of 40 and 44 (14.6\%, 95\% CI: 11.4-18.1\%) and the reduction among women being greatest between the ages of 35 and 39 (23.1\%, 95\% CI: 19.9-26.5\%). AIDS has also increased significantly the proportion of men and women who have no current partner, with the increase in men being greatest between the ages of 45 and $49(21.6 \%, 95 \% \mathrm{CI}$ : $17.9-26.5 \%)$ and the increase in women being greatest between the ages of 35 and 39 $(15.9 \%, 95 \%$ CI: $11.8-20.1 \%)$. AIDS has also reduced slightly the proportion of the population who are married, though this effect is relatively small. A more significant reduction in the proportion married is likely to have occurred as a result of reducing rates of entry into marriage over time (Garenne 2004), which are not allowed for in the model.

\subsection{The profile of new HIV infections, by sexual risk behaviour}

The profile of new HIV infections differs markedly by age, as shown in Figures 7a and 7b. Of the 371,000 (95\% CI: $341,000-406,000)$ new heterosexually transmitted HIV infections anticipated in $2010,36.9 \%(95 \%$ CI: $33.3 \%-40.8 \%)$ are expected to occur among individuals under the age of $25,54.9 \%$ (95\% CI: $51.1 \%-58.2 \%)$ are expected to occur among individuals aged $25-49$, and the remainder $(8.2 \%, 95 \%$ CI: $7.1 \%-9.1 \%)$ will occur in individuals aged 50 and older. Below age 25, 61.2\% (95\% CI: $55.3 \%$ $67.0 \%$ ) of new HIV infections are expected to occur in unmarried women, and a further $24.3 \%$ (95\% CI: $18.9 \%-28.0 \%$ ) are expected to occur in unmarried men in non-spousal relationships. The proportion of new HIV infections occurring in unmarried individuals is somewhat lower in the 25-49 age group (59.4\%, 95\% CI: $53.4 \%-65.6 \%$ ), with a significant proportion of new infections occurring in married individuals as a result of extramarital relationships $(12.9 \%, 95 \% \mathrm{CI}: 8.6 \%-17.2 \%)$, or as a result of being infected by their married partner $(26.8 \%, 95 \% \mathrm{CI}: 17.1 \%-36.2 \%)$. The proportions of new HIV infections in the 50+ age group occurring in married individuals is substantially greater, with $24.9 \%$ (95\% CI: $14.0 \%-35.8 \%$ ) of new infections occurring in married individuals as a result of extramarital relationships, and $37.6 \%(95 \% \mathrm{CI}$ : $23.8 \%-51.0 \%$ ) occurring as a result of married individuals being infected by their married partners. The latter are roughly equally split between men and women, while the former occur mainly in men. 
Figure 6: Changes in sexual behaviour between 1995 and 2005, by age and sex

(a) $\%$ of men with $>1$ partner

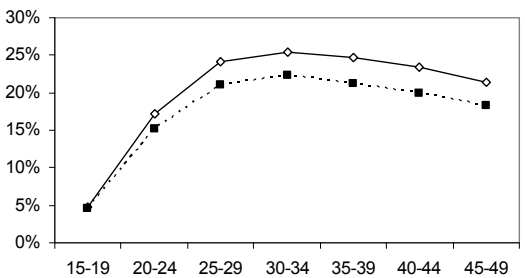

(c) \% of men who are abstinent

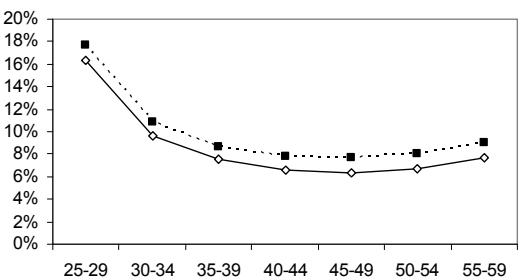

(e) \% of men who are married

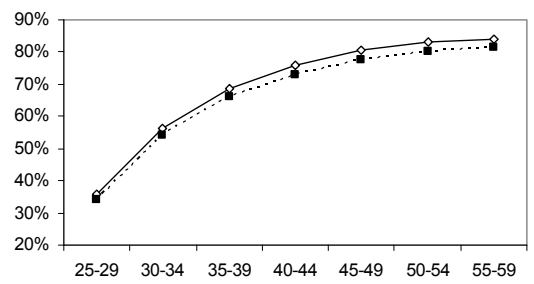

(b) $\%$ of women with $>1$ partner

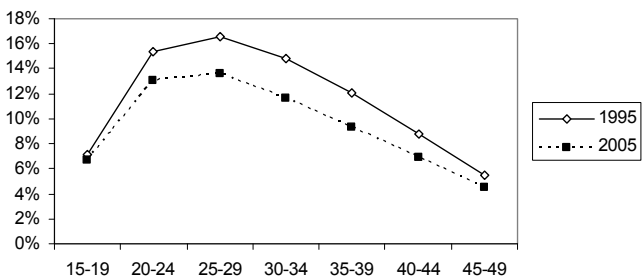

(d) \% of women who are abstinent

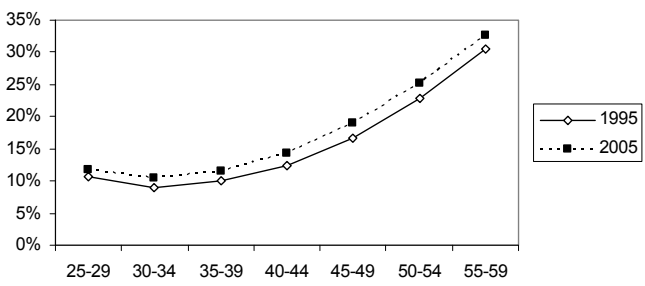

(f) \% of women who are married

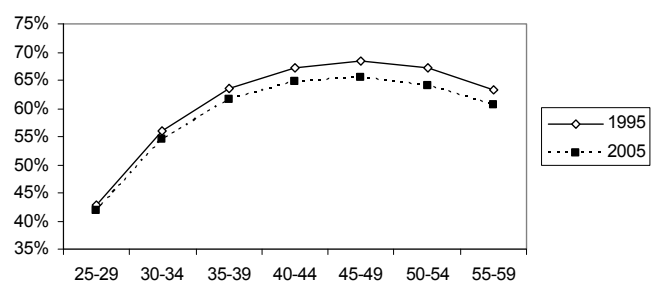

Proportions are means of posterior model predictions. Proportions in panels (a)-(d) have not been adjusted to reflect reporting bias (as in Figure 4), i.e., they represent the true proportions of individuals with the indicated numbers of partners.

The profile and number of new HIV infections has also changed significantly over time (Figures 7c and 7d). The estimated annual number of new HIV infections among individuals over the age of 10 rose from approximately 64,000 in 1990 (95\% CI: $52,000-78,000)$ to approximately 528,000 in 1998 (95\% CI: 490,000-567,000), and has declined steadily since then, mainly as a result of the assumed increases in condom usage. The proportion of new HIV infections occurring in men as a result of contact with sex workers has reduced significantly over the course of the epidemic, from $6.1 \%$ in 1990 (95\% CI: $5.1 \%-6.9 \%)$ to $1.3 \%$ in 2010 (95\% CI: $1.1 \%-1.5 \%)$. Over the same period, the proportion of new HIV infections occurring in married individuals as a 
result of infection by spouses has increased from $9.4 \%$ (95\% CI: $4.3 \%-16.3 \%)$ to $21.3 \%$ (95\% CI: $13.0 \%-29.6 \%$ ). Although the proportion of new HIV infections occurring in unmarried men (excluding those resulting from commercial sex) has remained relatively stable at around $25 \%$, the proportion of new HIV infections occurring in unmarried women has declined from $47.8 \%$ in 1990 (95\% CI: $41.0 \%-54.1 \%$ ) to $42.5 \%$ in 2010 (95\% CI: $37.8 \%-47.3 \%)$. The proportion of new HIV infections occurring in sex workers has remained negligibly small at all stages in the epidemic $(<0.2 \%)$, as this is a relatively small sub-population.

\section{Figure 7: Profile of new HIV infections according to type of sexual risk behaviour}

(a) Number of new HIV infections in 2010 , by age

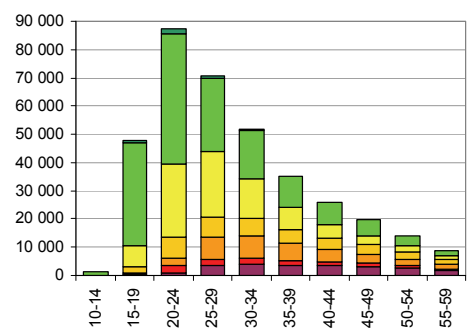

(c) Annual number of new HIV infections over age 10

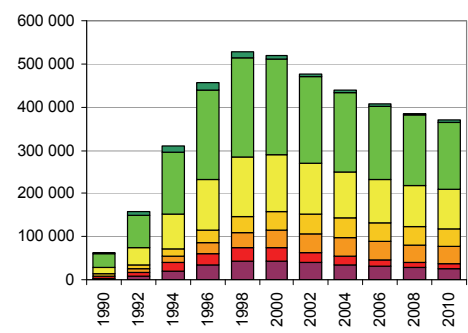

(b) Profile of new HIV infections in 2010, by age

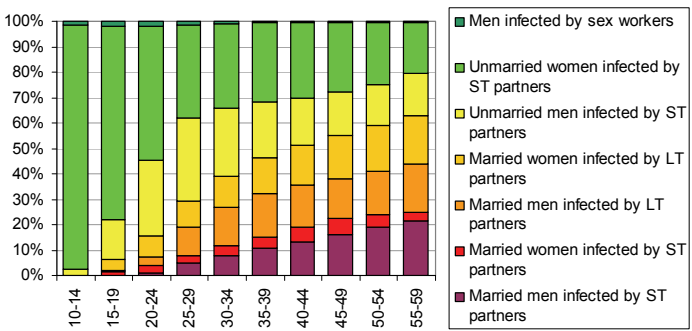

(d) Profile of new HIV infections over age 10, by year

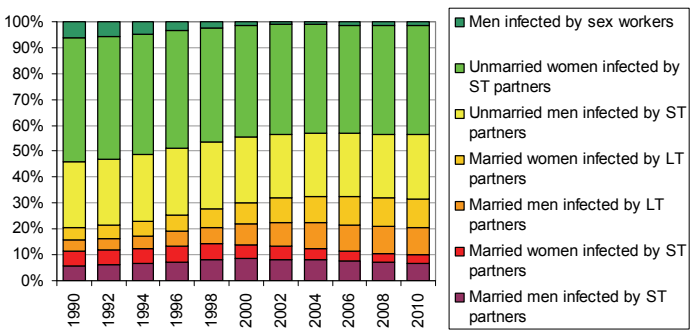

LT = long-term (spousal); ST = short-term (non-spousal). All proportions and numbers are posterior averages ( $95 \%$ confidence intervals not shown).

\subsection{The effect of changes in sexual behaviour}

The expected reductions in the number of new HIV infections over the 2010-2020 period, assuming that the behaviour changes occur in 2010, are shown in Figure 8. For the sake of comparison, Figure 8 also shows the reduction in new HIV infections that 
would have been expected over the 1990-2000 period, if the behaviour changes had occurred in 1990. In general, the behaviour changes have a significantly smaller effect on HIV incidence when introduced in the later stages of the HIV/AIDS epidemic (2010) than when introduced in the early stages of the epidemic (1990). As shown in Figure 7, a high level of HIV transmission is occurring in non-spousal relationships, and the greatest reductions in future HIV incidence would therefore be achieved by halving the rate of unprotected sex in non-spousal partnerships (35.9\%, 95\% CI: 31.8\%-40.0\%), and by halving the rate at which non-spousal partnerships are formed $(15.1 \%, 95 \% \mathrm{CI}$ : $13.0 \%-17.5 \%$ ). Halving the incidence of concurrent partnerships would be only slightly less effective than halving the incidence of all non-spousal partnerships, with an average reduction of $11.4 \%$ (95\% CI: $9.8 \%-13.1 \%)$ in HIV incidence. Halving the rate of sexual debut and doubling the incidence of marriage would have relatively little effect on the incidence of HIV. The latter could possibly even be associated with increases in HIV incidence, as condoms are used less frequently in marriage, and the frequency of sex in the early years of marriage is higher than that in non-spousal relationships.

\section{Figure 8: Percentage reductions in numbers of new HIV infections due to hypothetical behaviour changes}

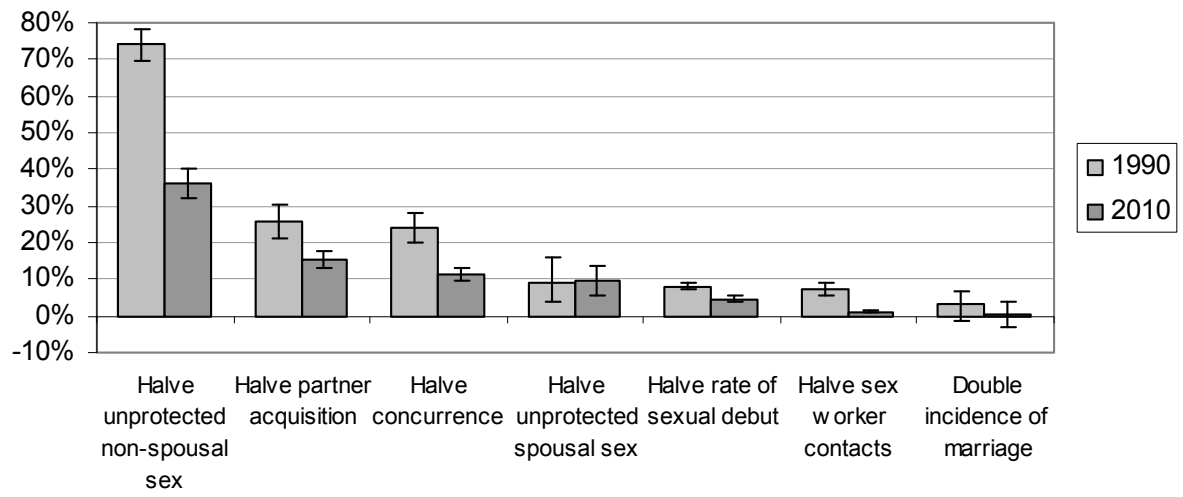

Percentage reductions are calculated over the 10 years following the change in the behaviour. Bars represent means of posterior model predictions and error bars represent $95 \%$ confidence intervals.

The relationship between the model parameters controlling behaviour change and the percentage reduction in HIV incidence is seldom linear. For example, there are diminishing marginal returns to reducing the proportion of non-spousal sex acts that are unprotected; the effect of reducing the proportion by $100 \%(64.5 \%, 95 \%$ interval: 
$57.5 \%-71.6 \%)$ is less than double the effect of reducing the proportion by $50 \%(35.9 \%$, 95\% interval: $31.8 \%-40.0 \%$ ). In contrast, there are increasing marginal returns to reducing the rate at which concurrent partnerships are formed; the effect of reducing the rate of secondary partner acquisition by $100 \%(38.6 \%, 95 \%$ interval: $31.9 \%-45.2 \%)$ is more than three times the effect of reducing the rate by $50 \%$ (11.4\%, $95 \%$ interval: 9.8\%-13.1\%). A similar difference in magnitude is estimated when considering the effect of this behaviour change in 1990: reducing the rate of secondary partner acquisition by $100 \%$ would have reduced the number of new HIV infections over the 1990-2000 period by $73.9 \%$ (95\% CI: $68.6 \%-77.9 \%)$, roughly three times the reduction that would have been achieved if the rate of secondary partner acquisition had been halved $(24.3 \%$, 95\% CI: $20.3 \%-27.8 \%)$. This suggests that the relationship between the rate of secondary partner acquisition and the incidence of HIV is highly non-linear. It also suggests that concurrent partnerships play an extremely important role in the spread of HIV in the early stages of the epidemic.

\subsection{Bias in reported sexual behaviour}

The bias parameters estimated in equation (2) can be exponentiated to obtain a ratio of the odds of having $n$ partners to the odds of reporting $n$ partners in an FTFI $\left(\exp \left(-b_{g, l, n}\right)\right)$. The posterior estimates of these odds ratios are shown in Table 5. The results suggest that there is significant underreporting of concurrent partnerships in FTFIs in South Africa, particularly among women and among married individuals. However, there does not appear to be significant under- or over-reporting of being single among unmarried individuals who are sexually experienced.

Table 5: Odds ratios for actual behaviour versus reported behaviour

\begin{tabular}{lllll}
\hline Marital status & Behaviour & Sex & Symbol & Odds ratio (95\% Cl) \\
\hline Unmarried & Multiple current partners & $\mathrm{M}$ & $\exp \left(-b_{1,1,2}\right)$ & $1.26(0.87-1.54)$ \\
& & $\mathrm{F}$ & $\exp \left(-b_{2,1,2}\right)$ & $6.3(3.9-8.2)$ \\
Married & Multiple current partners & $\mathrm{M}$ & $\exp \left(-b_{1,2,2}\right)$ & $3.3(2.0-4.3)$ \\
& & $\mathrm{F}$ & $\exp \left(-b_{2,2,2}\right)$ & $20.6(9.5-31.0)$ \\
Unmarried & No current partner & $\mathrm{M}$ & $\exp \left(-b_{1,1,0}\right)$ & $1.16(0.60-2.00)$ \\
& & $\mathrm{F}$ & $\exp \left(-b_{2,1,0}\right)$ & $0.66(0.46-1.06)$ \\
\hline
\end{tabular}




\section{Discussion}

A key conclusion from this analysis is that concurrent partnerships play a major role in the epidemiology of HIV in South Africa, accounting for roughly three-quarters of new HIV infections over the 1990-2000 period. It has been argued that the prevalence of partner concurrence in sub-Saharan Africa is higher than that in other global regions, and that concurrent partnerships may be one of the most important factors explaining the high prevalence of HIV in sub-Saharan Africa (Halperin and Epstein 2004). Mathematical models support the view that partner concurrence is a major factor promoting the spread of HIV (Morris and Kretzschmar 1997; Watts and May 1992), but there has been little effort made to estimate empirically the proportion of HIV incidence that is attributable to concurrent partnerships (Lurie and Rosenthal 2009).

It has also been hypothesized that late age at first marriage - and, more specifically, a long average interval between sexual debut and first marriage - is a key factor driving the spread of HIV, particularly in the countries of Southern Africa, where marriage tends to occur relatively late (Bongaarts 2007). The assumption underlying this argument is that marriage is protective against HIV. However, African studies that have examined the relationship between HIV and marital status have yielded conflicting findings, with some suggesting that marriage is associated with an increased risk of HIV (Auvert et al. 2001b; Clark 2004; Zuma et al. 2003), and others asserting the opposite (Shisana et al. 2004; Bongaarts 2007). Our analysis suggests that increasing the rate at which individuals marry would have very little effect on HIV incidence, and could possibly even increase HIV incidence, due to the relatively high frequency of unprotected sex in the early years of marriage. However, it is possible that this result may be a reflection of the simplifying assumptions made in the model - for example, the assumption that high risk and low risk individuals marry at the same rate, and the assumption that all marital relationships begin as non-marital relationships. Until there is further investigation into the plausibility of these assumptions, the result should be treated with caution.

In spite of the uncertainty regarding the HIV prevention benefits of earlier marriage, it is clear that most of the sexual transmission of HIV in South Africa is occurring in the context of non-spousal relationships. It is estimated that almost $80 \%$ of all HIV transmission in 2010 will occur in non-spousal or commercial sex relationships. This proportion has declined over time, and it is therefore important not to neglect the new HIV infections occurring in spousal relationships. It is also important to note that these infections occurring in spousal relationships are roughly equally split between married men infected by their wives and married women infected by their husbands, which contradicts the popular belief that HIV transmission occurring in spousal unions is almost exclusively male-to-female. Evidence from South Africa (Lurie et al. 2003) 
and other African countries (Tawfik and Watkins 2007; Orubuloye, Caldwell and Caldwell 1992; de Walque 2007) indicates that it is not uncommon for married women to engage in extramarital relationships, and a significant proportion of HIV infections in married women are likely to be the result of extramarital sex.

Mathematical models have an important role to play in understanding the patterns of sexual behaviour that favour the transmission of HIV. The models that have been developed to address this question can be classified as either static or dynamic: static models are designed to estimate the number of new HIV infections in the short-term future based on assumptions about current HIV prevalence levels (Gouws et al. 2006; Dunkle et al. 2008; Rehle et al. 1998), while dynamic models simulate the entire history of the epidemic and are capable of long-term projections of future HIV incidence (Brown and Peerapatanapokin 2004; van Vliet et al. 2001; Auvert et al. 2000). The advantage of the latter approach is that it provides more detailed output, and the model predictions of past HIV prevalence levels by age and sex provide a useful 'reality check' on the plausibility of the model. Like our model, other dynamic models of the HIV/AIDS epidemic in Africa have estimated that the proportion of new HIV infections occurring in non-spousal relationships is substantially greater than the proportion occurring in spousal relationships (van Vliet et al. 2001; Auvert et al. 2000). However, a recent static model of HIV transmission in Zambia and Rwanda estimated that more than half of all sexual transmission in these countries occurs between spousal partners (Dunkle et al. 2008), and another recent dynamic model of HIV transmission in Zambia estimated that almost half of all HIV transmission occurs in spousal unions (Leclerc, Matthews, and Garenne 2009). The relatively high contribution of spousal transmission in these models may be due to the relatively early age at first marriage in Zambia and Rwanda, compared to South Africa (Wellings et al. 2006). It is also likely that these results are partly due to the authors' assumptions that there is no under-reporting of non-spousal relationships, and that HIV transmission probabilities are the same in spousal and non-spousal relationships. Our analysis suggests that these assumptions are probably unrealistic in the South African setting.

Other dynamic models have focused much attention on the significant role of 'core groups' of individuals with high rates of partner change (typically sex workers and their clients) in spreading and sustaining epidemics of HIV and other STIs (Stigum, Falck, and Magnus 1994; Auvert et al. 2000; Brunham and Plummer 1990; Ghani and Aral 2005). Although this has been a popular avenue of research, some critics have argued that this focus on high risk groups, rather than on high risk behaviours, is stigmatizing and unhelpful (Wojcicki and Malala 2001; Varga 1997a), and others have argued that sexual behaviour patterns in the broader population may play a more important role in HIV transmission dynamics (Helleringer and Kohler 2007). Our analysis suggests that, although commercial sex accounted for around $6 \%$ of new HIV infections in South 
Africa in 1990, when the epidemic was in its early stages, the proportion of new HIV infections currently occurring in commercial sex encounters is only about $1 \%$. Interventions that target commercial sex workers are therefore likely to have relatively little impact on overall HIV incidence in a mature epidemic, i.e., once HIV has reached a high prevalence in the general population.

This analysis suggests that individuals tend to underreport concurrent partnerships substantially in FTFIs. Several alternative interview formats have been tested in an attempt to reduce this bias, including audio-computer-assisted self-interviews (ACASI), informal confidential voting interviews (ICVI), and self-administered questionnaires (SAQ). Using these more impersonal interview techniques, it has been found that women's odds of reporting multiple sexual partners are between 1.0 and 5.2 times those reported in FTFIs (Ghanem et al. 2005; Kissinger et al. 1999; Rogers et al. 2005; Gregson et al. 2004; Gregson et al. 2002), with this multiple being considerably higher in married women than in unmarried women (Gregson et al. 2002). Men's odds of reporting multiple partners in the more impersonal interview formats are between 1.1 and 1.7 times those in FTFIs (Ghanem et al. 2005; Rogers et al. 2005; Gregson et al. 2004; Gregson et al. 2002). The odds ratios that are shown in Table 5 are roughly consistent with the empirical estimates of bias, though the latter tend to be closer to one. It is likely that the alternative interview formats only partially reveal the extent of social desirability bias, since subjects will tend to worry about the confidentiality of their responses even when impersonal interview formats are used, and individuals who have had limited contact with computer technology are likely to be distrustful and fearful of computer-assisted methods (Mensch, Hewett, and Erulkar 2003). Although it is also possible that our model estimates of the extent of the bias may be exaggerated, it would be difficult to achieve consistency with observed age-specific HIV prevalence data if significantly lower levels of bias were assumed.

These results have important implications for second-generation HIV surveillance. The current guidelines for second-generation HIV surveillance encourage the use of sexual behaviour data to monitor epidemiological trends and progress in HIV prevention (Rehle et al. 2004; UNAIDS/WHO 2000). However, if self-reported sexual behaviour data are heavily distorted by social desirability bias, as this analysis suggests, differences between two surveys - in the recruitment and training of interviewers, the precise wording of the questions, the positioning of the questions within the questionnaire, and the overall length of the questionnaire - can cause substantial differences in the reporting of certain behaviours (Curtis and Sutherland 2004). HIV/AIDS education programmes, by actively promoting reductions in particular risk behaviours, may also influence the extent of social desirability bias (Caraël et al. 2006; Gregson et al. 2002). In addition, our analysis shows that significant reductions in proportions of individuals reporting multiple partners, and significant increases in 
proportions reporting sexual abstinence, can be expected to occur as a result of HIV/AIDS morbidity and mortality, in the absence of any deliberate change in sexual behaviour. Caution must therefore be applied in the interpretation of cross-survey comparisons that purport to show 'change' in sexual behaviour.

As noted previously, most deterministic models of sexual behaviour assign individuals to fixed 'risk groups', with no allowance for movements between risk groups, no explicit allowance for concurrent partnerships, and no distinction between spousal and non-spousal relationships. The model presented here avoids the serial monogamy assumption implicit in most deterministic models. In addition to stratifying the population on the basis of rates of partnership formation (the conventional approach in deterministic models), the model stratifies the population on the basis of the actual number of current partners, the risk groups of partners, and the nature of partnerships (spousal/non-spousal), allowing individuals to move between these states as they form new partnerships, marry, and separate. This more realistic approach has several advantages over the approach conventionally adopted in deterministic models. First, it allows for a more detailed assessment of which sexual behaviours are contributing most to the spread of HIV, and which forms of behaviour change would have the greatest impact. Second, sexual behaviour data can be used to determine model parameters more reliably. HIV/AIDS models have typically been calibrated to retrospective data on numbers of partners over some past period (Merli et al. 2006; Leclerc and Garenne 2007); our model, by contrast, is calibrated to data on numbers of current partners at the time of the survey. These data are arguably more important than retrospective data because they provide information on the extent of concurrent partnerships. Retrospective data are affected by recall bias, and, since most surveys ask respondents about the number of partners they have had in the last year, rather than the number of new partners in the last year, they provide little information on the rate at which new partnerships are formed.

Although the model of sexual behaviour is relatively detailed, a number of important simplifications have been necessary in the interests of computational speed. It is assumed that no individual ever has more than two current sexual partners. Although qualitative studies suggest that it is not uncommon for individuals to have more than two current partners (Parker et al. 2007; Varga 1997b; Twa-Twa, Nakanaabi, and Sekimpi 1997), a recent survey in Botswana suggests that the proportion of individuals with more than two current partners is only about $1 \%$ (Carter et al. 2007). This suggests that extending the model to allow for more than two current partners would not change the results substantially. Another simplification is the broad division of the population into two risk groups: those with a propensity for concurrent partnerships, and those who are serially monogamous. In reality there is likely to be much greater heterogeneity; some 'high risk' individuals may be involved in multiple partnerships for short periods 
of time on an irregular basis, while others may be inclined towards longer-term partner concurrence. Similarly, some 'low risk' individuals may be inclined towards long periods of sexual abstinence, while others may be sexually active almost all the time, with relatively short gaps between partnerships. Another simplification that limits the model is the division of the population into five-year age groups; more detailed division by single-year age would be appropriate at young ages, when rates of sexual debut and rates of marriage change relatively quickly (Schoen 1988).

A further limitation of the model is that the rates of transition between the various states are assumed to be independent of the length of time spent in the relevant state. A semi-Markov approach, allowing for duration-dependent transition rates, would be more realistic, particularly in the modelling of divorce and remarriage (Schoen 1988), dissolution of non-marital relationships, and rates of HIV disease progression. However, this would add considerably to the complexity of the model and the time taken to run the model, and would require the estimation of additional parameters from individual-level data. An individual-based stochastic modelling approach might be a more practical means of incorporating duration dependency into the Markov model that we have proposed (Hansen 2000). An added advantage of the stochastic approach is that it would achieve exact consistency between the number of male partnerships and female partnerships formed and/or dissolved (the balancing mechanism used in our model achieves only approximate consistency). However, the stochastic approach would be associated with a considerably greater computational burden when applying standard Bayesian approaches to uncertainty analysis (Sevcikova, Raftery, and Waddell 2006).

Although many sources of uncertainty have been considered in the uncertainty analysis, there remains substantial uncertainty regarding several of the sexual behaviour parameters. For example, there is little information on sexual behaviour at older ages, as most studies report on sexual activity in the 15 to 49 age range. Coital frequency and condom usage at older ages are therefore subject to substantial uncertainty. There is also much uncertainty regarding the commercial sex assumptions. Most of the studies on which the sex worker activity assumptions are based have been conducted in urban areas or on highways, and the assumed frequency of client contact would probably not be applicable to women who exchange sex for money in more remote rural areas or women who engage in transactional sex on an infrequent basis (Peltzer, Seoka, and Raphala 2004). The model parameterization is therefore based on a fairly narrow definition of commercial sex workers, i.e., women who earn all or most of their income by having sex in exchange for money. A more inclusive definition of commercial sex would yield a higher estimate of the rate at which men engage in commercial sex, and hence a higher estimate of the contribution of commercial sex to the transmission of HIV (Morison et al. 2001). There is also substantial uncertainty regarding the frequency 
with which men visit commercial sex workers, largely due to the uncertainty regarding the extent of male underreporting of this behaviour (Des Jarlais et al. 1999; Lau, Tsui, and Wang 2003; Morison et al. 2001).

There is also a degree of arbitrariness in several of the sexual behaviour parameters that have been chosen: e.g., the proportion of the population in the high risk group, the average duration of non-spousal relationships, and the relative rate of sexual debut in the low risk group. Although attempts were made to include these parameters in the uncertainty analysis, we found it to be extremely difficult to achieve convergence using the Metropolis algorithm if too many parameters were allowed to vary. This is probably because several of the sexual behaviour parameters are collinearly related to one another. In order to determine the sexual behaviour parameters more precisely, it will be necessary to improve the collection of sexual behaviour data. Including questions about durations of recent relationships and questions about whether respondents have ever had more than one sexual partner at a time would be particularly helpful. It is also worth noting that relatively few sexual behaviour surveys ask questions about the number of current partners, and this information is particularly important in fitting the model we have proposed.

Certain types of sexual intercourse have not been considered in this analysis, as they are not conventionally allowed for in models of HIV transmission in Africa. First, we have not considered the incidence of rape. South Africa has one of the highest rates of reported rape in the world (Kim, Martin, and Denny 2003), and this may be particularly significant in accounting for the high HIV prevalence in girls and young women. Second, the model does not allow for men to have sex with other men. Although sex between men is generally not believed to be common in South Africa, few surveys have examined this, and those that have are likely to be subject to significant underreporting. Perhaps particularly significant are the high levels of sex between men in prisons (Gear 2005). Evidence of sex between men in single-sex mine hostels has also been collected, although Moodie and Ndatshe (1994) argue that this ceased to be common after the 1970s. There is clearly a need for further research into the extent of HIV transmission in this marginalized group.

This is the first Bayesian analysis to integrate HIV prevalence data and sexual behaviour data in an attempt to understand the factors driving the transmission of HIV. Although HIV prevalence data and sexual behaviour data are affected by various biases, the relative levels of HIV prevalence and reported behaviour - by age, by sex, and by year - are nevertheless very informative of the parameters that drive the transmission of HIV. This analysis of sexual behaviour patterns in South Africa allows for both uncertainty regarding the extent of these biases, and uncertainty regarding the sexual behaviour and HIV transmission parameters. The model estimates are consistent with HIV prevalence data from antenatal surveys and household surveys, by age and by sex, 
and the model therefore appears to provide an acceptable approximation to current HIV transmission patterns in South Africa. Similar analyses of HIV transmission patterns in other African countries are urgently needed. 


\section{References}

Abdool Karim, Q.A., Abdool Karim, S.S., Soldan, K., and Zondi, M. (1995). Reducing the risk of HIV infection among South African sex workers: socioeconomic and gender barriers. American Journal of Public Health 85(11): 1521-1525. doi:10.2105/AJPH.85.11.1521.

Allen, C.F., Lees, S.S., Desmond, N.A., Der, G., Chiduo, B., Hambleton, I., Knight, L., Vallely, A., Ross, D.A., and Hayes, R.J. (2007). Validity of coital diaries in a feasibility study for the Microbicides Development Programme trial among women at high risk of HIV/AIDS in Mwanza, Tanzania. Sexually Transmitted Infections 83: 490-497. doi:10.1136/sti.2007.024810.

Allen, S., Tice, J., Van de Perre, P., Serufilira, A., Hudes, E., Nsengumuremyi, F., Bogaerts, J., Lindan, C., and Hulley, S. (1992). Effect of serotesting with counselling on condom use and seroconversion among HIV discordant couples in Africa. British Medical Journal 304(6842): 1605-1609. doi:10.1136/bmj.304.6842.1605.

Auvert, B., Ballard, R., Campbell, C., Caraël, M., Carton, M., Fehler, G., Gouws, E., MacPhail, C., Taljaard, D., Van Dam, J., and Williams, B. (2001a). HIV infection in a South African mining town is associated with herpes simplex virus-2 seropositivity and sexual behaviour. AIDS 15: 885-898. doi:10.1097/00002030-200105040-00009.

Auvert, B., Buanamico, G., Lagarde, E., and Williams, B. (2000). Sexual behaviour, heterosexual transmission, and the spread of HIV in Sub-Saharan Africa: a simulation study. Computers and Biomedical Research 33: 84-96. doi:10.1006/cbmr.1999.1533.

Auvert, B., Buvé, A., Ferry, B., Caraël, M., Morison, L., Lagarde, E., Robinson, N.J., Kahindo, M., Chege, J., Rutenberg, N., Musonda, R., Laourou, M., and Akam, E. (2001b). Ecological and individual level analysis of risk factors for HIV infection in four urban populations in sub-Saharan Africa with different levels of HIV infection. AIDS 15(Supplement 4): 15-30. doi:10.1097/00002030200108004-00003.

Baeten, J.M., Richardson, B.A., Lavreys, L., Rakwar, J.P., Mandaliya, K., Bwayo, J.J., and Kreiss, J.K. (2005). Female-to-male infectivity of HIV-1 among circumcised and uncircumcised Kenyan men. Journal of Infectious Diseases 191(4): 546-553. doi:10.1086/427656. 
Bah, S. (1999). The improvement of marriages and divorces statistics in South Africa: Relevance, registration issues and challenges. Discussion Paper 99-2. Population Studies Centre, University of Western Ontario. Available: http://sociology.uwo.ca/popstudies/dp/dp99-2.pdf. Accessed Oct 17, 2006.

Bauch, C. and Rand, D.A. (2000). A moment closure model for sexually transmitted disease transmission through a concurrent partnership network. Proceedings of the Royal Society of London, Series B. 267(1456): 2019-2027. doi:10.1098/rspb.2000.1244.

Bertozzi, S.M., Laga, M., Bautista-Arredondo, S., and Coutinho, A. (2008). Making HIV prevention programmes work. Lancet 372(9641): 831-844. doi:10.1016/S0140-6736(08)60889-2.

Blair, J.M., Hanson, D.L., Jones, J.L., and Dworkin, M.S. (2004). Trends in pregnancy rates among women with human immunodeficiency virus. Obstetrics and Gynecology 103(4): 663-668.

Blanc, A.K. and Rutenberg, N. (1991). Coitus and contraception: the utility of data on sexual intercourse for family planning programs. Studies in Family Planning 22(3): 162-176. doi:10.2307/1966643.

Bongaarts, J. (1989). A model of the spread of HIV infection and the demographic impact of AIDS. Statistics in Medicine 8(1): 103-120. doi:10.1002/sim.4780080111.

Bongaarts, J. (2007). Late marriage and the HIV epidemic in sub-Saharan Africa. Population Studies 61(1): 73-83. doi:10.1080/00324720601048343.

Bracher, M., Santow, G., and Watkins, S.C. (2004). Assessing the potential of condom use to prevent the spread of HIV: A microsimulation study. Studies in Family Planning 35(1): 48-64. doi:10.1111/j.1728-4465.2004.00005.x.

Brewer, D.D., Potterat, J.J., Muth, S.Q., Malone, P.Z., Montoya, P., Green, D.L., Rogers, H.L., and Cox, P.A. (2005). Randomized trial of supplementary interviewing techniques to enhance recall of sexual partners in contact interviews. Sexually Transmitted Diseases 32(3): 189-193. doi:10.1097/01.olq.0000154492.98350.90.

Brewis, A. and Meyer, M. (2005). Marital coitus across the life course. Journal of Biosocial Science 37(4): 499-518. doi:10.1017/S002193200400690X. 
Brown, M.S. (2000). Coitus, the proximate determinant of conception: inter-country variance in sub-Saharan Africa. Journal of Biosocial Science 32(2): 145-159. doi:10.1017/S0021932000001450.

Brown, T. and Peerapatanapokin, W. (2004). The Asian Epidemic Model: A process model for exploring HIV policy and programme alternatives in Asia. Sexually Transmitted Infections 80(Supplement 1): 19-24. doi:10.1136/sti.2004.010165.

Brunham, R.C. and Plummer, F.A. (1990). A general model of sexually transmitted disease epidemiology and its implications for control. Medical Clinics of North America 74(6): 1339-1352.

Budlender, D., Chobokoane, N., and Simelane, S. (2004). Marriage patterns in South Africa: Methodological and substantive issues. Southern African Journal of Demography 9(1): 1-26.

Bunnell, R., Ekwaru, J.P., Solberg, P., Wamai, N., Bikaako-Kajura, W., Were, W., Coutinho, A., Liechty, C., Madraa, E., Rutherford, G., and Mermin, J. (2006). Changes in sexual behavior and risk of HIV transmission after antiretroviral therapy and prevention interventions in rural Uganda. AIDS 20(1): 85-92. doi:10.1097/01.aids.0000196566.40702.28.

Caraël, M., Slaymaker, E., Lyerla, R., and Sarkar, S. (2006). Clients of sex workers in different regions of the world: hard to count. Sexually Transmitted Infections 82(Supplement 3): 26-33.

Carter, M.W., Kraft, J.M., Koppenhaver, T., Galavotti, C., Roels, T.H., Kilmarx, P.H., and Fidzani, B. (2007). "A bull cannot be contained in a single Kraal": Concurrent sexual partnerships in Botswana. AIDS and Behavior 11(6): 822-830. doi:10.1007/s10461-006-9203-6.

Clark, S. (2004). Early marriage and HIV risks in sub-Saharan Africa. Studies in Family Planning 35(3): 149-60. doi:10.1111/j.1728-4465.2004.00019.x.

Connolly, C., Shisana, O., Colvin, M., and Stoker, D. (2004). Epidemiology of HIV in South Africa - results of a national, community-based survey. South African Medical Journal 94(9): 776-781.

Curtis, S.L. and Sutherland, E.G. (2004). Measuring sexual behaviour in the era of HIV/AIDS: the experience of Demographic and Health Surveys and similar enquiries. Sexually Transmitted Infections 80(Supplement 2): 22-27. doi:10.1136/sti.2004.011650. 
De Walque, D. (2007). Sero-discordant couples in five African countries: implications for prevention strategies. Population and Development Review 33(3): 501-523. doi:10.1111/j.1728-4457.2007.00182.x.

Department of Health (1999). South Africa Demographic and Health Survey 1998: Full Report.

Department of Health (2004). South Africa Demographic and Health Survey 2003: Preliminary Report. Pretoria. Available: http://www.doh.gov.za/docs/. Accessed June 17, 2006.

Department of Health (2006). National HIV and Syphilis Prevalence Survey, South Africa 2005. Pretoria: Directorate of Epidemiology and Surveillance.

Des Jarlais, D.C., Paone, D., Milliken, J., Turner, C.F., Miller, H., Gribble, J., Shi, Q., Hagan, H., and Friedman, S.R. (1999). Audio-computer interviewing to measure risk behaviour for HIV among injecting drug users: a quasi-randomised trial. Lancet 353(9165): 1657-1661. doi:10.1016/S0140-6736(98)07026-3.

Dorrington, R.E., Johnson, L.F., Bradshaw, D., and Daniel, T. (2006). The Demographic Impact of HIV/AIDS in South Africa. National and Provincial Indicators for 2006. Cape Town: Centre for Actuarial Research, South African Medical Research Council and Actuarial Society of South Africa. Available: http://www.commerce.uct.ac.za/care.

Downs, A. and De Vincenzi, I. (1996). Probability of heterosexual transmission of HIV: relationship to the number of unprotected sexual contacts. Journal of Acquired Immune Deficiency Syndromes 11: 388-395.

Doyle, P.R. and Millar, D.B. (1990). A general description of an actuarial model applicable to the HIV epidemic in South Africa. Transactions of the Actuarial Society of South Africa 8: 561-593.

Dunkle, K.L., Jewkes, R.K., Brown, H.C., Gray, G.E., McIntryre, J. A., and Harlow, S.D. (2004). Transactional sex among women in Soweto, South Africa: prevalence, risk factors and association with HIV infection. Social Science and Medicine 59(8): 1581-1592. doi:10.1016/j.socscimed.2004.02.003.

Dunkle, K.L., Stephenson, R., Karita, E., Chomba, E., Kayitenkore, K., Vwalika, C., Greenberg, L., and Allen, S. (2008). New heterosexually transmitted HIV infections in married or cohabiting couples in urban Zambia and Rwanda: an analysis of survey and clinical data. Lancet 371(9631): 2183-2191. doi:10.1016/S0140-6736(08)60953-8. 
Eames, K.T. and Keeling, M.J. (2004). Monogamous networks and the spread of sexually transmitted diseases. Mathematical Biosciences 189(2): 115-130. doi:10.1016/j.mbs.2004.02.003.

Eaton, L., Flisher, A., and Aarø, L. (2003). Unsafe sexual behaviour in South African youth. Social Science and Medicine 56: 149-165. doi:10.1016/S02779536(02)00017-5.

Ferguson, N.M. and Garnett, G.P. (2000). More realistic models of sexually transmitted disease transmission dynamics: sexual partnership networks, pair models, and moment closure. Sexually Transmitted Diseases 27(10): 600-609. doi:10.1097/00007435-200011000-00008.

Ferry, B., Caraël, M., Buvé, A., Auvert, B., Laourou, M., Kanhonou, L., de Loenzien, M., Akam, E., Chege, J., and Kaona, F. (2001). Comparison of key parameters of sexual behaviour in four African urban populations with different levels of HIV infection. AIDS 15(Supplement 4): 41-50. doi:10.1097/00002030200108004-00005.

Garenne, M. (2004). Age at marriage and modernisation in sub-Saharan Africa. Southern African Journal of Demography 9(2): 59-79.

Garnett, G. and Anderson, R. (1996). Sexually transmitted diseases and sexual behaviour: insights from mathematical models. Journal of Infectious Diseases 174(Supplement 2): 150-160.

Garnett, G.P. and Anderson, R.M. (1995). Strategies for limiting the spread of HIV in developing countries: conclusions based on studies of the transmission dynamics of the virus. Journal of Acquired Immune Deficiency Syndromes 9(5): 500-513.

Garnett, G.P., Hughes, J.P., Anderson, R.M., Stoner, B.P., Aral, S.O., Whittington, W. L., Handsfield, H.H., and Holmes, K.K. (1996). Sexual mixing patterns of patients attending sexually transmitted diseases clinics. Sexually Transmitted Diseases 23(3): 248-257. doi:10.1097/00007435-199605000-00015.

Gear, S. (2005). Rules of engagement: Structuring sex and damage in men's prisons and beyond. Culture, Health and Sexuality 7(3): 195-208. doi:10.1080/13691050412331272668.

Gelman, A., Carlin, J., Stern, H., and Rubin, D. (2004). Bayesian Data Analysis. 2nd Edition. Boca Raton, Florida: Chapman \& Hall/CRC.

Ghanem, K.G., Hutton, H.E., Zenilman, J.M., Zimba, R., and Erbelding, E.J. (2005). Audio computer assisted self interview and face to face interview modes in 
assessing response bias among STD clinic patients. Sexually Transmitted Infections 81(5): 421-425. doi:10.1136/sti.2004.013193.

Ghani, A.C. and Aral, S.O. (2005). Patterns of sex worker-client contacts and their implications for the persistence of sexually transmitted infections. Journal of Infectious Diseases 191(Supplement 1): 34-41. doi:10.1086/425276.

Ghani, A.C., Donnelly, C.A., and Garnett, G.P. (1998). Sampling biases and missing data in explorations of sexual partner networks for the spread of sexually transmitted diseases. Statistics in Medicine 17(18): 2079-2097. doi:10.1002/(SICI)1097-0258(19980930)17:18<2079::AID-SIM902>3.0.CO;2H.

Gouws, E., White, P.J., Stover, J., and Brown, T. (2006). Short term estimates of adult HIV incidence by mode of transmission: Kenya and Thailand as examples. Sexually Transmitted Infections 82 (Supplement 3): 51-55. doi:10.1136/sti.2006.020164.

Granath, F., Giesecke, J., Scalia-Tomba, G., Ramstedt, K., and Forssman, L. (1991). Estimation of a preference matrix for women's choice of male sexual partner according to rate of partner change, using partner notification data. Mathematical Biosciences 107(2): 341-348. doi:10.1016/0025-5564(91)90013-9.

Gray, R., Wawer, M., Brookmeyer, R., Sewankambo, N., Serwadda, D., WabwireMangen, F., Lutalo, T., Li, X., Van Cott, T., and Quinn, T. (2001). Probability of HIV-1 transmission per coital act in monogamous, heterosexual, HIV-1discordant couples in Rakai, Uganda. Lancet 357: 1149-1153. doi:10.1016/S0140-6736(00)04331-2.

Greenblatt, R.M., Bacchetti, P., Barkan, S., Augenbraun, M., Silver, S., Delapenha, R., Garcia, P., Mathur, U., Miotti, P., and Burns, D. (1999). Lower genital tract infections among HIV-infected and high-risk uninfected women: findings of the Women's Interagency HIV Study (WIHS). Sexually Transmitted Diseases 26(3): 143-151. doi:10.1097/00007435-199903000-00004.

Gregson, S., Mushati, P., White, P.J., Mlilo, M., Mundandi, C., and Nyamukapa, C. (2004). Informal confidential voting interview methods and temporal changes in reported sexual risk behaviour for HIV transmission in sub-Saharan Africa. Sexually Transmitted Infections 80(Supplement 2): 36-42. doi:10.1136/sti.2004.012088.

Gregson, S., Zhuwau, T., Ndlovu, J., and Nyamukapa, C.A. (2002). Methods to reduce social desirability bias in sex surveys in low-development settings: experience in 
Zimbabwe. Sexually Transmitted Diseases 29(10): 568-575. doi:10.1097/00007435-200210000-00002.

Groeneveld, H. and Padayachee, N. (1992). A stochastic model for medium-term estimation of the prevalence of HIV infection in a South African heterosexual population. South African Medical Journal 81(2): 67-70.

Hallett, T.B., Aberle-Grasse, J., Bello, G., Boulos, L.M., Cayemittes, M.P., Cheluget, B., Chipeta, J., Dorrington, R., Dube, S., Ekra, A.K., Garcia-Calleja, J.M., Garnett, G.P., Greby, S., Gregson, S., Grove, J.T., Hader, S., Hanson, J., Hladik, W., Ismail, S., Kassim, S., Kirungi, W., Kouassi, L., Mahomva, A., Marum, L., Maurice, C., Nolan, M., Rehle, T., Stover, J., and Walker, N. (2006). Declines in HIV prevalence can be associated with changing sexual behaviour in Uganda, urban Kenya, Zimbabwe, and urban Haiti. Sexually Transmitted Infections 82(Supplement 1): 1-8. doi:10.1136/sti.2005.016014.

Hallett, T.B., Gregson, S., Lewis, J.J., Lopman, B. A., and Garnett, G.P. (2007). Behaviour change in generalised HIV epidemics: impact of reducing crossgenerational sex and delaying age at sexual debut. Sexually Transmitted Infections 83 (Supplement 1): 50-54. doi:10.1136/sti.2006.023606.

Hallman, K. (2004). Socioeconomic Disadvantage and Unsafe Sexual Behaviors among Young Women and Men in South Africa. Working Paper no. 190. New York: Population Council, Policy Research Division.

Halperin, D.T. and Epstein, H. (2004). Concurrent sexual partnerships help to explain Africa's high HIV prevalence: implications for prevention. Lancet 364(9428): 4-6. doi:10.1016/S0140-6736(04)16606-3.

Hankins, C., Tran, T., and Lapointe, N. (1998). Sexual behaviour and pregnancy outcome in HIV-infected women. Journal of Acquired Immune Deficiency Syndromes 18: 479-487.

Hansen, H.O. (2000). An AIDS model with reproduction - with an application based on data from Uganda. Mathematical Population Studies 8(2): 175-203.

Hargreaves, J.R., Bonell, C.P., Morison, L.A., Kim, J.C., Phetla, G., Porter, J.D., Watts, C., and Pronyk, P.M. (2007). Explaining continued high HIV prevalence in South Africa: socioeconomic factors, HIV incidence and sexual behaviour change among a rural cohort, 2001-2004. AIDS 21 (Supplement 7): 39-48. doi:10.1097/01.aids.0000300534.97601.d6. 
Hayes, R.J., Schulz, K.F., and Plummer, F.A. (1995). The cofactor effect of genital ulcers on the per-exposure risk of HIV transmission in sub-Saharan Africa. Journal of Tropical Medicine and Hygiene 98: 1-8.

Helleringer, S. and Kohler, H.P. (2007). Sexual network structure and the spread of HIV in Africa: evidence from Likoma Island, Malawi. AIDS 21(17): 2323-2332. doi:10.1097/QAD.0b013e328285df98.

Hewett, P.C., Mensch, B.S., and Erulkar, A.S. (2004). Consistency in the reporting of sexual behaviour by adolescent girls in Kenya: a comparison of interviewing methods. Sexually Transmitted Infections 80(Supplement 2): 43-48. doi:10.1136/sti.2004.013250.

Høgsborg, M. and Aaby, P. (1992). Sexual relations, use of condoms and perceptions of AIDS in an urban area of Guinea-Bissau with a high prevalence of HIV-2. In: Dyson, T. (ed.) Sexual Behaviour and Networking: Anthropological and Sociocultural Studies on the Transmission of HIV. Liège, Belgium: Derouaux.

Hornsby, P.P. and Wilcox, A.J. (1989). Validity of questionnaire information on frequency of coitus. American Journal of Epidemiology 130(1): 94-99.

Human Sciences Research Council (2002). South African national HIV prevalence, behavioural risks and mass media household survey 2002. Available: http://www.hsrcpress.ac.za. Accessed Feb 18, 2009.

Jewkes, R., Vundule, C., Maforah, F., and Jordaan, E. (2001). Relationship dynamics and teenage pregnancy in South Africa. Social Science and Medicine 52(5): 733-44. doi:10.1016/S0277-9536(00)00177-5.

Jewkes, R.K., Nduna, M., Jama, P.N., Dunkle, K.L., and Levin, J.B. (2002). Steadys, roll-ons and hit and runs: using indigenous typology to measure number of sexual partners [Abstract TuPpE2069]. Paper presented at: 14th International AIDS Conference, Barcelona, Spain, July 2002.

Jochelson, K., Mothibeli, M., and Leger, J.P. (1991). Human immunodeficiency virus and migrant labor in South Africa. International Journal of Health Services 21(1): 157-173.

John, A.M. (1991). A model of HIV-1 transmission for urban areas of Africa. Theoretical Population Biology 39(2): 148-169. doi:10.1016/00405809(91)90033-C. 
Johnson, L.F. (2008). The interaction between HIV and other sexually transmitted infections in South Africa: a model-based evaluation. [PhD thesis]. Cape Town: University of Cape Town, Department of Actuarial Science.

Johnson, L.F. and Dorrington, R.E. (2006). Modelling the demographic impact of HIV/AIDS in South Africa and the likely impact of interventions. Demographic Research 14(22): 541-574. doi:10.4054/DemRes.2006.14.22.

Johnson, L.F., Dorrington, R.E., and Matthews, A.P. (2007). An investigation into the extent of uncertainty surrounding estimates of the impact of HIV/AIDS in South Africa. South African Journal of Science 103: 135-140.

Kaplan, E.H. (1990). Modeling HIV infectivity: Must sex acts be counted? Journal of Acquired Immune Deficiency Syndromes 3: 55-61.

Katz, I. and Low-Beer, D. (2008). Why has HIV stabilized in South Africa, yet not declined further? Age and sexual behavior patterns among youth. Sexually Transmitted Diseases 35(10): 837-842. doi:10.1097/OLQ.0b013e31817c0be5.

Kelly, K. (2000). Communicating for action: A contextual evaluation of youth responses to HIV/AIDS. Department of Health. Available: http://www.cadre.org.za. Accessed October 12, 2006.

Kim, J.C., Martin, L.J., and Denny, L. (2003). Rape and HIV post-exposure prophylaxis: addressing the dual epidemics in South Africa. Reproductive Health Matters 11(22): 101-112. doi:10.1016/S0968-8080(03)02285-7.

Kissinger, P., Rice, J., Farley, T., Trim, S., Jewitt, K., Margavio, V., and Martin, D.H. (1999). Application of computer-assisted interviews to sexual behavior research. American Journal of Epidemiology 149(10): 950-954.

Korenromp, E.L., Van Vliet, C., Bakker, R., De Vlas, S.J., and Habbema, J.D.F. (2000). HIV spread and partnership reduction for different patterns of sexual behaviour a study with the microsimulation model STDSIM. Mathematical Population Studies 8(2): 135-173.

Küstner, H., Swanevelder, J., and Van Middelkoop, A. (1994). National HIV surveillance - South Africa, 1990-1992. South African Medical Journal 84: 195-199.

Lagarde, E., Enel, C., and Pison, G. (1995). Reliability of reports of sexual behavior: a study of married couples in rural west Africa. American Journal of Epidemiology 141(12): 1194-1200. 
Lau, J.T., Tsui, H.Y., and Wang, Q.S. (2003). Effects of two telephone survey methods on the level of reported risk behaviours. Sexually Transmitted Infections 79(4): 325-331. doi:10.1136/sti.79.4.325.

Laumann, E.O., Gagnon, J.H., Michael, R.T. and Michaels, S. (1994). The Social Organization of Sexuality: Sexual Practices in the United States. Chicago: University of Chicago Press.

Leclerc, P.M. and Garenne, M. (2007). Inconsistencies in age profiles of HIV prevalence: A dynamic model applied to Zambia. Demographic Research 16(5): 121-140. doi:10.4054/DemRes.2007.16.5.

Leclerc, P.M., Matthews, A.P., and Garenne, M.L. (2009). Fitting the HIV epidemic in Zambia: a two-sex micro-simulation model. PLoS One 4(5): 5439. doi:10.1371/journal.pone.0005439.

Leigh, B.C., Gillmore, M.R., and Morrison, D.M. (1998). Comparison of diary and retrospective measures for recording alcohol consumption and sexual activity. Journal of Clinical Epidemiology 51(2): 119-127. doi:10.1016/S08954356(97)00262-X.

Lurie, M.N. and Rosenthal, S. (2009 forthcoming). Concurrent partnerships as a driver of the HIV epidemic in sub-Saharan Africa? The evidence is limited. AIDS and Behavior. doi:10.1007/s10461-009-9583-5.

Lurie, M.N., Williams, B.G., Zuma, K., Mkaya-Mwamburi, D., Garnett, G.P., Sweat, M.D., Gittelsohn, J., and Abdool Karim, S.S. (2003). Who infects whom? HIV-1 concordance and discordance among migrant and non-migrant couples in South Africa. AIDS 17(15): 2245-2252. doi:10.1097/00002030-200310170-00013.

Mahiane, G., Legeai, C., Latouche, A., Taljaard, D., Puren, A., Peillon, A., Bretagnolle, J., Ndong Nguema, P., Gassiat, E., and Auvert, B. (2008). Transmission probabilities of $\mathrm{HIV}$ and $\mathrm{HSV}-2$ and interaction between these viruses: a longitudinal study in a township of South Africa. Paper presented at: XVII International AIDS Conference, Mexico City, Mexico, August 3-8, 2008.

Manhart, L.E., Aral, S.O., Holmes, K.K., and Foxman, B. (2002). Sex partner concurrency: measurement, prevalence, and correlates among urban 18-39-yearolds. Sexually Transmitted Diseases 29(3): 133-143. doi:10.1097/00007435200203000-00003.

Mastro, T.D., Satten, G.A., Nopkesorn, T., Sangkharomya, S. and Longini, I.M. (1994). Probability of female-to-male transmission of HIV-1 in Thailand. Lancet 343(8891): 204-207. doi:10.1016/S0140-6736(94)90990-3. 
McAuliffe, T.L., DiFranceisco, W., and Reed, B.R. (2007). Effects of question format and collection mode on the accuracy of retrospective surveys of health risk behavior: a comparison with daily sexual activity diaries. Health Psychology 26(1): 60-67. doi:10.1037/0278-6133.26.1.60.

McClelland, R.S., Hassan, W.M., Lavreys, L., Richardson, B.A., Mandaliya, K., Ndinya-Achola, J., Jaoko, W., Kurth, A.E., and Baeten, J.M. (2006). HIV-1 acquisition and disease progression are associated with decreased high-risk sexual behaviour among Kenyan female sex workers. AIDS 20(15): 1969-1973. doi:10.1097/01.aids.0000247119.12327.e6.

Meekers, D. and Van Rossem, R. (2005). Explaining inconsistencies between data on condom use and condom sales. BMC Health Services Research 5(1): 5. doi:10.1186/1472-6963-5-5.

Mensch, B.S., Hewett, P.C., and Erulkar, A.S. (2003). Reporting of sensitive behavior by adolescents: a methodological experiment in Kenya. Demography 40(2): 247-268. doi:10.1353/dem.2003.0017.

Merli, M.G., Hertog, S., Wang, B., and Li, J. (2006). Modelling the spread of HIV/AIDS in China: The role of sexual transmission. Population Studies 60(1): 1-22. doi:10.1080/00324720500436060.

Moatti, J.P., Prudhomme, J., Traore, D.C., Juillet-Amari, A., Akribi, H.A., and Msellati, P. (2003). Access to antiretroviral treatment and sexual behaviours of HIVinfected patients aware of their serostatus in Côte d'Ivoire. AIDS 17 (Supplement 3): 69-77. doi:10.1097/00002030-200317003-00010.

Moodie, T.D. and Ndatshe, V. (1994). Going for Gold: Men, Mines and Migration. Johannesburg: Witwatersrand University Press.

Morison, L., Weiss, H.A., Buvé, A., Caraël, M., Abega, S.C., Kaona, F., Kanhonou, L., Chege, J., and Hayes, R.J. (2001). Commercial sex and the spread of HIV in four cities in sub-Saharan Africa. AIDS 15(Supplement 4): 61-69. doi:10.1097/00002030-200108004-00007.

Morris, M. and Kretzschmar, M. (1997). Concurrent partnerships and the spread of HIV. AIDS 11(5): 641-648. doi:10.1097/00002030-199705000-00012.

Mpofu, E., Flisher, A.J., Bility, K., Onya, H., and Lombard, C. (2006). Sexual partners in a rural South African setting. AIDS and Behavior 10(4): 399-404. doi:10.1007/s10461-005-9037-7. 
Myer, L. (2005). Barrier methods. In: Abdool Karim, S.S. and Abdool Karim, Q. (eds.) HIV/AIDS in South Africa. Cape Town: Cambridge University Press.

Nnko, S., Boerma, J.T., Urassa, M., Mwaluko, G., and Zaba, B. (2004). Secretive females or swaggering males? An assessment of the quality of sexual partnership reporting in rural Tanzania. Social Science and Medicine 59(2): 299-310. doi:10.1016/j.socscimed.2003.10.031.

Orubuloye, I.O., Caldwell, J.C., and Caldwell, P. (1992). Sexual networking and the risk of AIDS in Southwest Nigeria. In: Dyson, T. (ed.) Sexual Behaviour and Networking: Anthropological and Socio-cultural Studies on the Transmission of $H I V$. Liège, Belgium: Derouaux.

Oster, E. (2005). Sexually transmitted infections, sexual behavior, and the HIV/AIDS epidemic. Quarterly Journal of Economics 120(2): 467-515. doi:10.1162/0033553053970160.

Padian, N. S., Shiboski, S. C., and Jewell, N. P. (1990). The effect of number of exposures on the risk of heterosexual HIV transmission. Journal of Infectious Diseases 161(5): 883-887.

Parker, W., Makhubele, B., Ntlabati, P., and Connolly, C. (2007). Concurrent sexual partnerships amongst young adults in South Africa: Challenges for HIV prevention communication. Centre for AIDS Development, Research and Evaluation. Available: http://www.cadre.org.za. Accessed June 7, 2008.

Peltzer, K., Seoka, P., and Raphala, S. (2004). Characteristics of female sex workers and their HIV/AIDS/STI knowledge, attitudes and behaviour in semi-urban areas in South Africa. Curationis March 2004: 4-11.

Pettifor, A.E., Hudgens, M.G., Levandowski, B.A., Rees, H.V., and Cohen, M.S. (2007). Highly efficient HIV transmission to young women in South Africa. AIDS 21(7): 861-865. doi:10.1097/QAD.0b013e3280f00fb3.

Pettifor, A.E., Measham, D.M., Rees, H.V., and Padian, N.S. (2004a). Sexual power and HIV risk, South Africa. Emerging Infectious Diseases 10(11): 1996-2004.

Pettifor, A.E., van der Straten, A., Dunbar, M.S., Shiboski, S.C., and Padian, N.S. (2004b). Early age of first sex: a risk factor for HIV infection among women in Zimbabwe. AIDS 18(10):1435-1442. doi:10.1097/01.aids.0000131338.61042.b8.

Piot, P., Bartos, M., Larson, H., Zewdie, D., and Mane, P. (2008). Coming to terms with complexity: a call to action for HIV prevention. Lancet 372(9641): 845-859. doi:10.1016/S0140-6736(08)60888-0. 
Porter, L., Hao, L., Bishai, D., Serwadda, D., Wawer, M.J., Lutalo, T., and Gray, R. (2004). HIV status and union dissolution in sub-Saharan Africa: the case of Rakai, Uganda. Demography 41(3): 465-482. doi:10.1353/dem.2004.0025.

Ramjee, G., Weber, A.E., and Morar, N.S. (1999). Recording sexual behavior: comparison of recall questionnaires with a coital diary. Sexually Transmitted Diseases 26(7): 374-380. doi:10.1097/00007435-199908000-00002.

Ramjee, G., Williams, B., Gouws, E., Van Dyck, E., De Deken, B., and Abdool Karim, S. (2005). The impact of incident and prevalent herpes simplex virus-2 infection on the incidence of HIV-1 infection among commercial sex workers in South Africa. Journal of Acquired Immune Deficiency Syndromes 39(3): 333-339. doi:10.1097/01.qai.0000144445.44518.ea.

Rees, H., Beksinska, M.E., Dickson-Tetteh, K., Ballard, R.C., and Htun, Y. (2000). Commercial sex workers in Johannesburg: risk behaviour and HIV status. South African Journal of Science 96: 283-284.

Rehle, T., Lazzari, S., Dallabetta, G., and Asamoah-Odei, E. (2004). Second-generation HIV surveillance: better data for decision-making. Bulletin of the World Health Organization 82(2): 121-127.

Rehle, T.M., Saidel, T.J., Hassig, S.E., Bouey, P.D., Gaillard, E.M., and Sokal, D.C. (1998). AVERT: A user-friendly model to estimate the impact of HIV/sexually transmitted disease prevention interventions on HIV transmission. AIDS 12(Supplement 2): 27-35.

Reproductive Health Research Unit (2004). HIV and sexual behaviour among young South Africans: A national survey of 15-24 year olds. Joint publication of Reproductive Health Research Unit and loveLife. Available at www.rhru.co.za/images/Docs/national\%20survey\%20RHRU.pdf. Accessed May 8, 2004.

Rogers, S.M., Willis, G., Al-Tayyib, A., Villarroel, M.A., Turner, C.F., Ganapathi, L., Zenilman, J., and Jadack, R. (2005). Audio computer assisted interviewing to measure HIV risk behaviours in a clinic population. Sexually Transmitted Infections 81(6): 501-507. doi:10.1136/sti.2004.014266.

Ross, A., Van der Paal, L., Lubega, R., Mayanja, B.N., Shafer, L.A., and Whitworth, J. (2004). HIV-1 disease progression and fertility: the incidence of recognized pregnancy and pregnancy outcome in Uganda. AIDS 18: 799-804. doi:10.1097/00002030-200403260-00012. 
Schall, R. (1990). On the maximum size of the AIDS epidemic among the heterosexual black population in South Africa. South African Medical Journal 78(9): 507-510.

Schoen, R. (1988). Practical uses of multistate population models. Annual Review of Sociology 14: 341-361. doi:10.1146/annurev.so.14.080188.002013.

Schoub, B.D., Smith, A.N., Lyons, S.F., Johnson, S., Martin, D.J., McGillivray, G., Padayachee, G.N., Naidoo, S., Fisher, E.L., and Hurwitz, H.S. (1988). Epidemiological considerations of the present status and future growth of the acquired immunodeficiency syndrome epidemic in South Africa. South African Medical Journal 74(4): 153-157.

Sevcikova, H., Raftery, A.E., and Waddell, P.A. (2006). Assessing uncertainty in urban simulations using Bayesian melding. Working Paper no. 57. Seattle: Centre for Statistics and the Social Sciences, University of Washington. Available: http://www.csss.washington.edu/Papers. Accessed May 19, 2006.

Shisana, O., Rehle, T., Simbayi, L.C., Parker, W., Zuma, K., Bhana, A., Connolly, C., Jooste, S., and Pillay, V. (2005). South African National HIV Prevalence, HIV Incidence, Behaviours and Communication Survey, 2005. Cape Town: HSRC Press. Available: http://www.hsrcpress.ac.za. Accessed December 1, 2005.

Shisana, O., Zungu-Dirwayi, N., Toefy, Y., Simbayi, L.C., Malik, S., and Zuma, K. (2004). Marital status and risk of HIV infection in South Africa. South African Medical Journal 94(7): 537-543.

Statistics South Africa (2006). Marriages and divorces, 2004. Report No. 03-07-01. Pretoria. Available: http://www.statssa.gov.za/publications/Report-03-0701/Report-03-07-012004.pdf. Accessed August 2, 2008.

Stigum, H., Falck, W., and Magnus, P. (1994). The core group revisited: the effect of partner mixing and migration on the spread of gonorrhea, chlamydia, and HIV. Mathematical Biosciences 120(1): 1-23. doi:10.1016/0025-5564(94)90036-1.

Tawfik, L. and Watkins, S.C. (2007). Sex in Geneva, sex in Lilongwe, and sex in Balaka. Social Science and Medicine 64(5): 1090-1101. doi:10.1016/j.socscimed.2006.10.002.

Terceira, N., Gregson, S., Zaba, B., and Mason, P R. (2003). The contribution of HIV to fertility decline in rural Zimbabwe, 1985-2000. Population Studies 57(2): 149-164. doi:10.1080/0032472032000097074. 
Turner, C.F., Ku, L., Rogers, S.M., Lindberg, L.D., Pleck, J.H., and Sonenstein, F.L. (1998). Adolescent sexual behavior, drug use, and violence: increased reporting with computer survey technology. Science 280(5365): 867-873. doi:10.1126/science.280.5365.867.

Twa-Twa, J., Nakanaabi, I., and Sekimpi, D. (1997). Underlying factors in female sexual partner instability in Kampala. Health Transition Review 7(Supplement): 83-88. doi:10.1287/inte.28.3.84.

UNAIDS/WHO (2000). Guidelines for Second Generation HIV Surveillance.

Van der Ploeg, C.P.B., Van Vliet, C., De Vlas, S., Ndinya-Achola, J.O., Fransen, L., Van Oortmarssen, G.J., and Habbema, J.D.F. (1998). STDSIM: a microsimulation model for decision support in STD control. Interfaces 28: 84-100.

Van Tonder, J.L. (1985). Fertility survey 1982: Data concerning the Black population of South Africa. Report S-129. Pretoria: Human Sciences Research Council.

Van Vliet, C., Meester, E.I., Korenromp, E.L., Singer, B., Bakker, R., and Habbema, J.D. (2001). Focusing strategies of condom use against HIV in different behavioural settings: an evaluation based on a simulation model. Bulletin of the World Health Organization 79(5): 442-454.

Varga, C.A. (1997a). The condom conundrum: barriers to condom use among commercial sex workers in Durban, South Africa. African Journal of Reproductive Health 1(1): 74-88. doi:10.2307/3583277.

Varga, C.A. (1997b). Sexual decision-making and negotiation in the midst of AIDS: youth in KwaZulu-Natal, South Africa. Health Transition Review 7(Supplement 3): 45-67.

Watts, C.H. and May, R.M. (1992). The influence of concurrent partnerships on the dynamics of HIV/AIDS. Mathematical Biosciences 108(1): 89-104. doi:10.1016/0025-5564(92)90006-I.

Weller, S. and Davis, K. (2004). Condom effectiveness in reducing heterosexual HIV transmission (Cochrane Review). In: The Cochrane Library. Chichester, UK: John Wiley \& Sons.

Wellings, K., Collumbien, M., Slaymaker, E., Singh, S., Hodges, Z., Patel, D., and Bajos, N. (2006). Sexual behaviour in context: A global perspective. Lancet 368(9548): 1706-1728. doi:10.1016/S0140-6736(06)69479-8. 
Williams, B., Gilgen, D., Campbell, C., Taljaard, D., and MacPhail, C. (2000). The natural history of HIV / AIDS in South Africa: A biomedical and social survey in Carletonville. Johannesburg: Council for Scientific and Industrial Research.

Wojcicki, J.M. and Malala, J. (2001). Condom use, power and HIV/AIDS risk: Sexworkers bargain for survival in Hillbrow/Joubert Park/Berea, Johannesburg. Social Science and Medicine 53(1): 99-121. doi:10.1016/S0277-9536(00)003154.

Zuma, K., Gouws, E., Williams, B., and Lurie, M. (2003). Risk factors for HIV infection among women in Carletonville, South Africa: Migration, demography and sexually transmitted diseases. International Journal of STD and AIDS 14(12): 814-817. doi:10.1258/095646203322556147. 
Johnson et al: Sexual behaviour patterns in South Africa and their association with the spread of HIV 